NASA Technical Memorandum 105979

AIAA-93-0596

\title{
Takeoff/Approach Noise for a Model Counterrotation Propeller with a Forward-Swept Upstream Rotor
}

Richard P. Woodward

Lewis Research Center

Cleveland, Ohio

David G. Hall

Sverdrup Technology, Inc.

Lewis Research Center Group

Brook Park, Ohio

and

Gary G. Podboy and Robert J. Jeracki

Lewis Research Center

Cleveland, Ohio

Prepared for the

31st Aerospace Sciences Meeting and Exhibit

sponsored by the American Institute of Aeronautics and Astronautics

Reno, Nevada, January 11-14, 1993

\section{N/SN}




\title{
TAKEOFF/APPROACH NOISE FOR A MODEL COUNTERROTATION PROPELLER WITH A
}

\section{FORWARD-SWEPT UPSTREAM ROTOR}

\author{
Richard P. Woodward \\ National Aeronautics and Space Administration \\ Lewis Research Center \\ Cleveland, Ohio 44135 \\ David G. Hall \\ Sverdrup Technology, Inc. \\ Lewis Research Center Group \\ Brook Park, Ohio 44142 \\ Gary G. Podboy and Robert J. Jeracki \\ National Aeronautics and Space Administration \\ Lewis Research Center \\ Cleveland, Ohio 44135
}

\section{$\underline{\text { Abstract }}$}

A scale model of a counterrotating propeller with forward-swept blades in the forward rotor and aftswept blades in the aft rotor (designated F39/A31) has been tested in the NASA Lewis 9- by 15-Ft Anechoic Wind Tunnel. This paper presents aeroacoustic results at a takeoff/approach condition of Mach 0.20. Laser Doppler velocimeter results taken in a plane between the two rotors are also included to quantify the interaction flow field. The intention of the forward-swept design is to reduce the magnitude of the forward rotor tip vortex and/or wakes which impinge on the aft rotor, thus lowering the interaction tone levels. A reference model propeller (designated F31/A31), having aft-swept blades in both rotors, was also tested. Aeroelastic performance of the F39/A31 propeller was disappointing. The forward rotor tip region tended to untwist toward higher effective blade angles under load. The forward rotor also exhibited steady state blade flutter at speeds and loadings well below the design condition. The noise results, based on sideline acoustic data, show that the interaction tone levels were up to $8 \mathrm{~dB}$ higher with the forward-swept design compared to those for the reference propeller at similar operating conditions, with these tone level differences extending down to lower propeller speeds where flutter did not occur. These acoustic results are for a poorlyperforming forward-swept propeller. It is quite possible that a properly-designed forward-swept propeller would exhibit substantial interaction tone level reductions.

\section{Introduction}

Modern high-performance turboprop aircraft offer the promise of considerable fuel savings while still allowing for a cruise speed similar to that of current turbofan aircraft. Advanced counterrotation propellers may offer from 8 to 10 percent additional fuel savings over similar single rotation propellers at cruise conditions. ${ }^{1}$ However, there is considerable concern about the potential noise generated by such an aircraft, which includes both cruise noise and community noise during takeoff and landing.

The noise signature of a counterrotation propeller includes rotor-alone tones, generated by forward and aft rotor interaction with the flow field, and interaction tones which arise from aeroacoustic interaction between the rotor flow fields. Figure 1 shows a typical sound pressure level spectrum from a counterrotating propeller. At takeoff/approach conditions $\left(\mathbf{M}_{\infty}=0.2\right)$ interaction tones dominate the spectrum above the fundamental blade passage frequency. Interaction tone levels have been well correlated with the aft rotor interacting with the forward rotor tip vortex and viscous wake. In the past, the interaction tone levels have been somewhat reduced ${ }^{2}$ by increasing the rotorrotor spacing, or by reducing the aft rotor diameter so 
that it does not significantly interact with the upstream rotor tip vortex.

Another method proposed for reducing the interaction tone levels is to employ a "forward-swept" forward rotor in an effort to reduce the magnitude of the forward rotor tip vortex, and provide more wake decay through increased separation at outboard locations. This noise reduction concept is illustrated in the sketch of Fig. 2, and can be explained by discussing how the wake flow of a forward-swept rotor might be different from that of a conventional aft-swept rotor. The tip vortex which results from an aft-swept rotor is really a combination of two separate vortices - the vortex which forms along the tip of the blade and a vortex which forms along the swept leading edge. On an aft-swept blade, this leading edge vortex begins to form inboard, follows the leading edge outward, and is convected downstream at a location near the blade tip. This leading edge vortex is expected to merge with the blade tip vortex into a single vortex. On a forward-swept blade, if a leading edge vortex forms, it starts to do so near the tip, and would be expected to follow the leading edge radially inward, and be convected downstream at a radial location inboard of the tip vortex. Therefore, the tip and leading edge vortices would exist independently downstream of the rotor. At a given operating condition, each of these two separate vortices would be expected to be weaker than the combined vortex which exists downstream of the aft-swept blade, and consequently would be expected to generate less interaction noise. Additionally, the forward-swept geometry results in a greater rotor-rotor axial separation in the tip region which would allow for more dissipation of the tip region vortex before it interacts with the aft rotor.

This paper presents results for a model forwardswept counterrotation turboprop, designated F39/A31, which was tested in the NASA Lewis 9 - by $15-\mathrm{Ft}$ Anechoic Wind Tunnel. Data were taken at Mach 0.2, which is representative of takeoff/approach conditions. Figure 3 shows the F39/A31 propeller. Figure 4 shows the propeller installed in the 9 - by $15-\mathrm{Ft}$ tunnel with associated acoustic instrumentation. Acoustic data were taken with fixed microphones which were attached to the tunnel wall, with an axially-translating microphone probe which was mounted to the tunnel floor, and with a polar microphone probe, attached to the aft propeller housing, which could take both sideline and circumfer- ential acoustic surveys. A reference aft-swept propeller, designated F31/A31, was also tested at similar operating conditions to provide an aeroacoustic comparison. Data were taken for several blade setting angles, at propeller axis angles-of-attack up to $16^{\circ}$, and at two rotor-rotor spacings. Acoustic results presented in this report are for the propeller operating at $0^{\circ}$ angle-of-attack and were taken with the polar probe. Additionally, laser Doppler velocimeter measurements were made between the blade rows for selected propeller operating conditions to further understand the inter-blade flow structure.

Acoustic performance of the forward-swept propeller did not meet expectations. In general, the tone levels (both rotor-alone and interaction) were higher than those observed for the reference propeller. This was due, in part, to problems with the aeromechanical forward-swept blade design which resulted in significant tip untwist (increased pitch) under load, and a tendency for the blade to go into incipient flutter, which limited the test matrix to below-design rotative speeds. It is quite possible that the adverse acoustic effects observed for the F39/A31 propeller are not typical of a properly designed forward-swept propeller.

\section{Apparatus}

\section{Anechoic Wind Tunnel}

The NASA Lewis 9- by 15-Ft Anechoic Wind Tunnel is located in the low-speed return leg of the 8- by 6-Ft Supersonic Wind Tunnel. The maximum airflow velocity in the test section is slightly over Mach 0.20 , which provides a takeoff/approach environment. The tunnel acoustic treatment provides anechoic conditions down to a frequency of $250 \mathrm{~Hz}$, which is lower than the range of test propeller acoustic tones. 3,4

\section{Acoustic Instrumentation}

The acoustic data presented in this paper were acquired with the polar microphone probe, which may be seen in the photograph of Fig. 4. Figure 5 shows a cross-sectional sketch of the installed model and polar probe. The probe was instrumented with a $0.64 \mathrm{~cm}$ (0.25 in.) diameter condenser microphone with a "bullet nose" flow protector. The polar probe was 
mounted to the downstream propeller housing and surveyed a cylindrical surface at a radius of $61 \mathrm{~cm}$ (24 in.) from the propeller axis. Results from the polar probe represent free-field data for an uninstalled propeller. The probe could take sideline surveys of $\pm 45^{\circ}$ relative to the aft propeller plane $\left(45^{\circ} \leq \theta \leq 135^{\circ}\right)$. The polar probe sideline surveys were taken at a constant angular velocity relative to the aft propeller plane, and required approximately $180 \mathrm{sec}$ to complete.

A computer-controlled FFT analyzer was used to acquire 62 representative sound pressure level spectra ( 0 to $10 \mathrm{kHz}, 32 \mathrm{~Hz}$ bandwidth). A computer analysis program then isolated desired tone orders $(\mathrm{BPF}, \mathrm{F}+\mathrm{A}$ interaction, etc.) to generate tone sideline directivities. Acoustic comparisons presented in this paper are for polar sideline surveys which were taken in the horizontal plane toward the far tunnel wall (right side in Fig. 4). These surveys are representative of the propeller noise field since there is essentially no circumferential variation in the noise field for $0^{\circ}$ propeller axis angle-of-attack. ${ }^{2}$

\section{Test Propellers}

Figure 3 is a photograph of the forward-swept F39/A31 propeller. A reference aft-swept propeller (F31/A31) used the same aft rotor. Table 1 presents selected design parameters for the two propellers. The propellers were tested in the $12+10$ blade configuration. All data were acquired with an $18.24 \mathrm{~cm}$ (7.22 in.) spacing between rotor-rotor pitch axes, with the exception of one F39/A31 test which was performed at a closer $14.99 \mathrm{~cm}$ (5.90 in.) spacing (Table 2). The propeller installation in the $9-$ by $15-\mathrm{Ft}$ Wind Tunnel was powered by two independent air turbine drives, allowing operation of the forward and aft rotors at different speeds. The two rotors were operated at about $50 \mathrm{rpm}$ difference to avoid the higher test rig vibration experienced with nearly equal speeds. The unequal blade numbers facilitated spectral separation of the various propeller tone orders.

Aeromechanical performance of the forwardswept F39 rotor was disappointing. The rotor tended to go into flutter at rotative speeds above 75 percent design - thus limiting the test matrix. Also, excessive tip untwist tended to increase the effective blade angle in the tip region during operation. Various attempts were made to improve the rotor aeroelastic stability (see Fig. 6). The forward-extending leading edge was clipped at first 10 percent, then 15 percent of the tip chord. The tip-region airfoil was sufficiently thin that this clipping had little effect on the leading edge radius. Additionally, the leading edge was rounded to a $4.06 \mathrm{~cm}$ ( $1.6 \mathrm{in}$.) diameter. These efforts produced a marginal improvement in the blade aeroelastic stability.

It was determined from these early F39 tests that the blade aeromechanical performance could be improved with changes in the method of graphite fiber layup. (The rotors were of titanium spar/graphite fiber layup composite construction.) A second set of F39 blades were built with a modified layup procedure to enhance stiffness. Testing with these blades showed a marginal improvement in aeromechanical performance. After initial testing showed little aeroacoustic improvement, the tip regions of these blades were also modified as shown in Fig. 6.

Table 2 lists the propeller test configurations which were used in this study. The aft-swept F31/A31 propeller showed no aeromechanical anomalies, and was tested, as planned, at two blade setting angles. (Data were also taken for a higher-loading condition, but corresponding F39/A31 runs were not possible.)

\section{Aerodynamic Results}

Data for the forward-swept F39/A31 and the reference aft-swept F31/A31 propellers were taken on two propeller operating lines, with the F39 rotor setting angles at $\beta=32.0^{\circ}$ and $35^{\circ}$, and F31 rotor at $\beta=34.1^{\circ}$ and $38.0^{\circ}$. This corresponds to low and intermediate blade loadings for an actual aircraft application. Higher F39 blade setting angles could not be tested due to the flutter problem. Table 3 is a listing of selected aerodynamic results for the F39/A31 and F31/A31 propellers. Figure 7 shows the total power density (PQAT) based on the forward rotor annulus area as a function of the forward rotor advance ratio, $\mathrm{J}_{1}$. Data points for similar operating conditions for the F39/A31 and F31/A31 propeller are displaced slightly due to differences in rotor diameter, and consequently, advance ratio for the same rotative speed. The propeller operating map for the forward rotor (Fig. 8) shows similar performance on each operating line for F39 and F31. The common aft rotor, 
A31, for which the blade setting angle remained constant at $\beta=38.2^{\circ}$, showed essentially the same aerodynamic performance for all test conditions (Fig. 9). Comparisons should be valid between F39/A31 and F31/A31 for a particular propeller operating line with similar PQAT and $\mathrm{J}$ values.

\section{Acoustic Results}

Acoustic results will be presented from data taken along a $61 \mathrm{~cm}(24 \mathrm{in}$.) sideline by the polar microphone probe. Results will be presented in terms of sound pressure level (SPL) spectra and sideline tone directivities.

Figures 10 and 11 compare SPL spectra for the two propellers operating on the intermediate operating line. The F39/A31 propeller spectrum is for the remanufactured F39 blade shape without tip modifications (see Table 2). Figure 10 compares spectra at 75 percent design propeller speed, while Fig. 11 shows results at the maximum safe test speed for the F39/A31 propeller ( 83 percent design) versus 85 percent design speed for the reference, F31/A31 propeller. Maximum levels for selected tone orders are indicated on these spectra. Tone levels for F39/A31 are consistently higher than corresponding levels for F31/A31 for both rotor speeds, with differences typically being on the order of $8 \mathrm{~dB}$. If the poor acoustic performance of F39/A31 were due to its tip leading edge flexibility and subsequent higher loading and/or the flutter problem, one would expect that differences in tone level would be negligible, or even reversed at the lower operating speed. However, significantly higher tone level differences were observed throughout the range of propeller test speeds.

Figures 12 and 13 show sideline directivities for the $\mathrm{F}+\mathrm{A}$ and $2 \mathrm{~F}+\mathrm{A}$ interaction tone orders for the two propellers on the intermediate operating line (same conditions as for Figs. 10 and 11). The forward-swept concept was designed to minimize the forward rotor tip vortex and thereby significantly reduce the interaction tone levels. In these results the forward-swept propeller is clearly seen to have higher tone level directivities for both tone orders at 75 percent speed (Fig. 12) and at 83/85 percent speed (Fig. 13).

Broadband levels were determined from examination of representative SPL spectra for the F39/A31 and
F31/A31 propellers at the $\mathrm{F}+\mathrm{A}$ and $2 \mathrm{~F}+\mathrm{A}$ tone frequencies. Broadband curves are also presented in Figs. 12 and 13 which likewise show higher levels associated with the forward-swept F39/A31 propeller. Windmill data from earlier propeller tests conducted in the NASA Lewis 9- $x$ 15-Ft Tunnel suggest that tunnel background levels are typically about $86 \mathrm{~dB}$ in the frequency region of the present propeller $\mathrm{F}+\mathrm{A}$ tone, and $84 \mathrm{~dB}$ in the region of the $2 \mathrm{~F}+\mathrm{A}$ tone, indicating that tunnel background levels are not influencing these results.

Figures 14 to 16 show maximum tone levels along a $61 \mathrm{~cm}$ (24 in.) sideline as a function of percent propeller design speed. Results for the two propellers for the low blade loading operating line are shown in part (a) of each figure, while part (b) of each figure is for the intermediate operating line. The F39 blade configuration for the low loading operating line $\left(\beta=32.0^{\circ}\right)$ was with the originally-manufactured blade with 15 percent of the leading edge clipped (see Fig. 6). Two F39 blade configurations are represented for the intermediate operating line results. The remanufactured blades had the design tip shape and were run with $\beta=35.0^{\circ}$. The originally-manufactured blades had 15 percent of the leading edge clipped and the tip rounded to a $4.06 \mathrm{~cm}$ (1.60 in.) diameter, and were operated with $\beta=35.3^{\circ}$.

Figure 14 shows the maximum forward rotor BPF tone as a function of propeller speed. There is little tone level difference between F39 and F31 at speeds below 85 percent for the low blade loading (Fig. 14(a)), but both F39 modes show considerably higher tone levels relative to the F31 rotor at the intermediate blade loading (Fig. 14(b)) at speeds above 75 percent. This may be related to the flutter condition experienced by these blades at higher rotative speeds, and/or the tendency for the forward-swept rotor tip to flex under load.

Corresponding results for the $\mathrm{F}+\mathrm{A}$ and $2 \mathrm{~F}+\mathrm{A}$ interaction tones are shown on Figs. 15 and 16. Tone levels for the F39 rotor are consistently higher than those for the reference F31 rotor. Also, the difference in tone levels appears to be just as large (sometimes larger) at the lower propeller speeds as for the higher speeds. One would expect that if the poor aeromechanical performance of the F39 rotor were adversely affecting the interaction tone levels, this difference 
between F39 and F31 would be most pronounced at higher propeller speeds where the F39 rotor experienced the most tip flex and flutter. However, these results suggest that the forward-swept F39/A31 propeller may be fundamentally noisier than the reference F31/A31 propeller regardless of propeller speed, although the forward-swept noise reduction concept may be viable for a properly-designed propeller.

\section{$\underline{\text { Laser Doppler Velocimeter Measurements }}$}

Laser Doppler velocimeter measurements were made to define the wake flow generated by the forward-swept and aft-swept forward rotors. All three velocity components were measured in selected axial planes downstream of the rotors. When each velocity measurement was made the instantaneous angular position of each rotor was recorded, allowing detailed blade-to-blade variations in the flow to be determined. Figure 17 shows axial velocities measured in the wake of each of the forward rotors, F39 and F31. Both sets of data were obtained in the same constant axial plane, just upstream of the aft rotor. This plane is depicted in the sketch above each data plot. The view here is from behind the measurement plane looking upstream. Here the axial velocities are shown plotted relative to the circumferential position of the front rotor, which would be rotating counter-clockwise in this view. Any influence of the aft rotor would be smeared out circumferentially. In generating these plots, the data of the twelve individual blade passages were averaged into one "composite" passage. The composite passage flows of each rotor are plotted here, and they are shown repeated to illustrate any transitions which might occur across the boundaries of the passage. This composite passage is shown a total of three times for each rotor. These data are for propeller operation on the low blade loading operating line at 85 percent propeller design speed. At this condition the forwardswept F39 blades did not flutter. The F31 blade setting angle was $35.0^{\circ}$ for the laser data, slightly different from the $34.1^{\circ}$ for which acoustic data have been presented.

Two significant differences can be seen in the velocity fields of the two propellers. One is a result of differences in the blade wakes shed from the two sets of forward rotor blades. While at inboard radial locations the blade wakes are similar, at outer locations the F39 blade wakes appear to be much wider than those of the F31 blades. It was first thought that this region of increased wake thickness downstream of the F39 blades might be due to flow separation from the blade surfaces. LDV measurements within the F39 blade passages could indicate if separation occurred; unfortunately, intrablade measurements were not made at this operating condition. It should be noted, however, that similar F39 blade wakes were measured at each of the other operating conditions at which LDV data were obtained, and that intrablade measurements made at other operating conditions did not show any flow separation. This increased blade wake thickness might simply be a consequence of wake spreading. Wider wakes might be expected at these outer measurement locations since they are further downstream from the blade due to the forward sweep of the trailing edge.

The other noticeable difference between the two flow fields results from the tip vortices shed from the blades. The vortices shed from the forward-swept blades are shown to produce larger axial velocity perturbations than those of the aft-swept rotor. Mean axial velocities as low as $46 \mathrm{~m} / \mathrm{sec}(150 \mathrm{ft} / \mathrm{sec})$ and as high as $137 \mathrm{~m} / \mathrm{sec}(450 \mathrm{ft} / \mathrm{sec})$ were measured within the tip vortices shed from the forward-swept blades; while mean axial velocities measured within the aftswept blade tip vortices varied from 52 to $119 \mathrm{~m} / \mathrm{sec}$ (170 to $390 \mathrm{ft} / \mathrm{sec}$ ). The axial velocity perturbations induced by the tip vortices are also shown to occur over a larger area downstream of the forward-swept blades. These data suggest that the tip vortices shed from the forward-swept blades are stronger than those produced by the aft-swept blades.

The data plotted in Fig. 18 provide some insight as to why the forward-swept blades could be expected to generate stronger tip vortices than the aft-swept blades. In this figure the axial and tangential velocities of Fig. 17 have been replotted; but here they are shown after the data obtained at each of the different radial locations have been circumferentially averaged. Hence, Fig. 18 shows radial distributions of circumferentially averaged axial and tangential velocity similar to those that might be determined by radially traversing a low frequency-response pitot-static pressure probe at this axial location. In order to show both velocity components on the same graph, the freestream velocity of $67 \mathrm{~m} / \mathrm{sec}(220 \mathrm{ft} / \mathrm{sec})$ was subtracted from the axial velocities. The data measured downstream of the aft-swept rotor shows both the axial and 
tangential velocities increasing gradually with decreasing radius from the tip until each distribution peaks inboard of 50 percent span. These data indicate that the loading of the F31 blades peaked at an inboard location and that the tips of the blades were relatively lightly loaded. This is the sort of radial loading distribution that one would expect for a properly designed rotor of a counterrotating configuration. In contrast, the velocity distributions measured downstream of the F39 blades indicate much higher loadings in the tip region. Since tip vortex strength is expected to increase with tip loading, the F39 blades would be expected to generate stronger tip vortices. The high tip loading on the F39 blades is probably related to the high flexibility of these blades. The tip regions may be twisting under load to higher than expected effective blade angles. Similar velocity profiles taken at 75 percent design speed also showed evidence of high tip loading (blade untwist), suggesting that noise generation from higher tip loading may be typical of the entire range ( 70 to 85 percent design) of propeller test speeds.

It is important to note that the axial velocity contours presented in Fig. 17 for the two front rotors shown evidence of only a single vortex in the flow downstream of each blade. As discussed previously, when a leading edge vortex forms on an aft-swept blade it migrates radially outward and merges with the tip vortex. Therefore, in this case only a single vortex per blade would be expected. In contrast, if a leading edge vortex were to form on a forward-swept blade it would move inward and be convected downstream at a radial location inboard of the tip vortex. Therefore, if leading edge vortices were forming on these forward-swept blades, they would appear in the velocity contours as separate regions of very steep axial velocity gradient. These are not shown to occur in the wake flow of the forward-swept blades. This probably means that the leading edges of these blades were not swept forward enough to allow the formation of leading edge vortices at this operating condition. This is significant since this noise reduction concept relies, at least in part, on the ability of the forward-swept blades to generate separate leading edge and tip vortices; individually these vortices would be weaker than a single tip vortex, and therefore, would be expected to generate less interaction noise. Since no leading edge vortex is shown to occur, little if any noise reduction would be expected. As discussed above, at a similar operating condition, the forward-swept blades are thought to have actually generated stronger tip vortices than the aft-swept blades. This supports the acoustic findings presented earlier which indicated that the aftswept F31/A31 propeller performed better acoustically than did the forward-swept F39/A31 configuration.

\section{Effect of Rotor-Rotor Spacing}

Reference 2 presented results for two counterrotation propellers which were previously tested in the same facility. These propellers shared a common aftswept forward rotor (designated F7), but had different aft rotors. The A7 rotor had essentially the same diameter as did the $\mathrm{F} 7$ rotor; however, the $\mathrm{A} 3$ rotor was designed with a smaller diameter in an effort to avoid interaction with the forward rotor tip vortex, and thereby result in lower interaction tone levels. The A3 rotor was otherwise designed with a larger chord and increased blade setting angle to achieve aerodynamic performance similar to that of the A7 rotor. Maximum interaction tone levels as a function of rotor-rotor spacing for these two propellers showed the tone levels to decrease more rapidly with spacing for the F7/A3 propeller. The A3 rotor was apparently reacting with the more rapidly dissipating upstream rotor viscous wake rather than the tip vortex which was "missing" it.

The following discussion compares acoustic results for the F7/A7 and F7/A3 propellers with those of the current study in an effort to gain a further insight into the F39/A31 interaction tone mechanism. The F39/A31 propeller was run at two rotor-rotor spacings - the closer spacing corresponds to the maximum spacing run with the propellers of reference 2. Unfortunately, the F39 rotor was slightly modified when it was operated at the closer rotor-rotor spacing (see Table 2) by having 15 percent of the leading edge chord clipped.

Figure 19 shows that the F39/A31 and F31/A31 propellers operating on the "intermediate-loading" operating line have a comparable aerodynamic performance to that of the F7/A7 and F7/A3 propellers of reference 2. This was a chance result in that the propellers of reference 2 had different blade numbers (11/9) and rotor tip diameters. However, it is possible to compare operating points with similar $\mathrm{J}$ and power loading. 
Figures 20 and 21 show the effect of rotor-rotor spacing on the $\mathrm{F}+\mathrm{A}$ interaction tone level. At a $\mathrm{J}_{1}$ value of about 1.11 (Fig. 20) the tone level for the reference F7/A3 propeller is seen to be much lower than the corresponding level for the F7/A7 propeller at the $14.99 \mathrm{~cm}$ (5.90 in.) spacing. As previously discussed, the higher level for the F7/A7 propeller is thought to be caused by tip vortex interaction. Maximum $\mathrm{F}+\mathrm{A}$ tone levels for the F39/A31 propeller with spacing seem to be a continuation of the curve established by the F7/A7 propeller, suggesting that tip vortex interaction may be the mechanism for the F39/A31 interaction tone. A similar result is seen for the higher propeller speed results of Fig. 21.

\section{Concluding Discussion}

A scale model of a counterrotating propeller with a forward-swept forward rotor was aeroacoustically tested in the NASA Lewis 9- by 15-Ft Anechoic Wind Tunnel. A reference propeller with aft-swept blades in both rotors was also tested in the same facility at the same operating conditions. It was expected that the forward-swept propeller concept would generate a significantly-reduced forward rotor tip vortex and wake, resulting in significantly lower interaction tone levels for this propeller.

The aeroelastic performance of the forward-swept propeller did not meet expectations. The forward rotor was prone to enter flutter at modest propeller speeds above 75 percent of design, depending on blade loading. Additionally, the tip region of the forward-swept rotor proved to be excessively flexible, resulting in additional effective blade pitch near the tip region. Several modifications were made to the F39 rotor to attempt to improve its aeroelastic performance. These were to (a) clip the blade leading edge tip chord by 15 percent, (b) round the tip leading edge, and (c) remanufacture the forward-swept rotor to improve the blade stiffness. These changes gave only a modest improvement in the forward-swept rotor's aeroelastic performance.
The aeroacoustic performance of the forwardswept propeller was also disappointing. Fundamental rotor-alone tones for the forward-swept model tended to be higher than those for the aft-swept reference propeller. Comparison of the interaction tones showed that levels for the forward-swept design were consistently higher by up to $8 \mathrm{~dB}$. This difference was observed at all propeller speeds tested from 70 to 85 percent design. Laser Doppler velocimeter data gathered in the plane between the rotors for both models indicated that the tip vortex induced by the forward swept upstream rotor was larger and stronger than that measured for the aft-swept forward rotor.

It is important to stress that the forward-swept F39 rotor in this study did not perform well mechanically and aerodynamically. It is quite possible that the adverse acoustic effects observed for the F39/A31 propeller are not typical of a properly designed forward-swept propeller.

\section{$\underline{\text { References }}$}

1. Mikkelson, D.C., Mitchell, G.A., and Bober, L.J., "Summary of recent NASA Propeller Research," Aerodynamics and Acoustics of Propellers, AGARD CP- 366, AGARD. Neuilly-Sur-Seine, France, 1985, pp. $12-1$ to $12-24$. (Also NASA TM-83733, 1984.)

2. Woodward, R.P., "Noise of Two High-Speed Model Counterrotation Propellers at Takeoff/Approach Conditions," Journal of Aircraft, Vol. 29, No. 4, July-August 1992, pp. 679-685.

3. Dahl, M.D., and Woodward, R.P., "Comparison Between Design and Installed Acoustic Characteristics of NASA 9- by 15-Ft Low-Speed Wind Tunnel Acoustic Treatment," NASA TP-2996, April 1990.

4. Dahl, M.D., and Woodward, R.P., "Acoustical Evaluation of the NASA Lewis 9- by 15-Ft Low Speed Wind Tunnel," NASA TP-3274, Nov. 1992. 
F31/A31, Reference aft-swept forward rotor

Number of blades ${ }^{\mathrm{a}}$

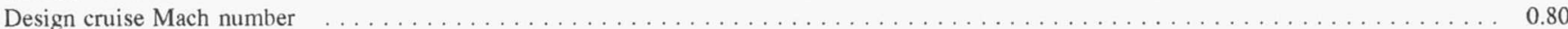

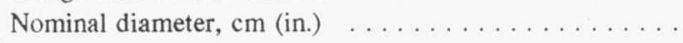

$65.18 / 62.91,(25.66 / 24.77)$

Nominal design cruise corrected tip speed, $\mathrm{m} / \mathrm{sec}$, (ft/sec)

$256 / 251,(839 / 810)$

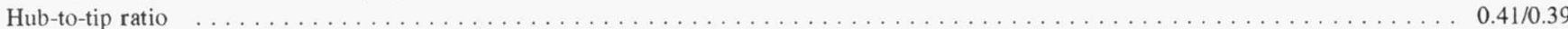

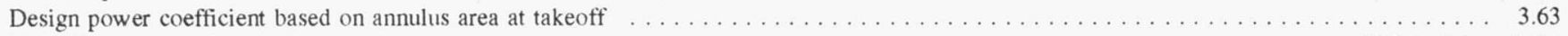

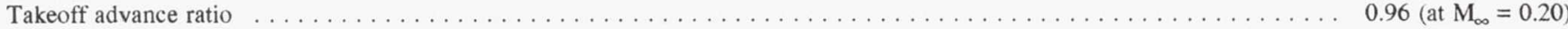

F39/A31, Forward-swept forward rotor

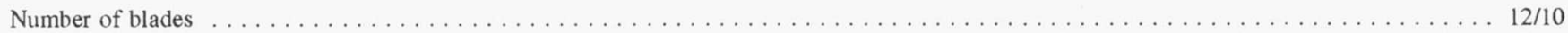

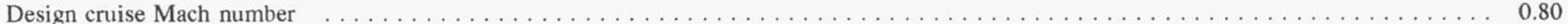

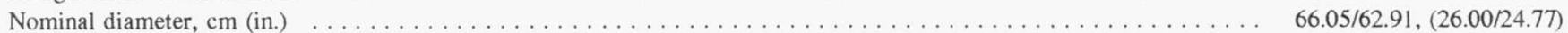

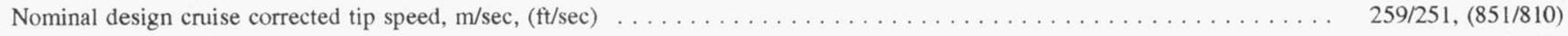

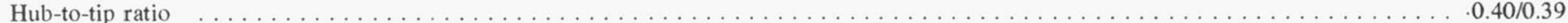

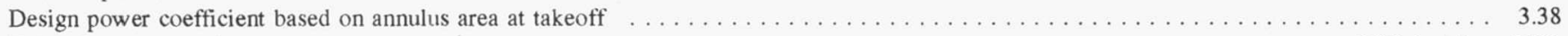

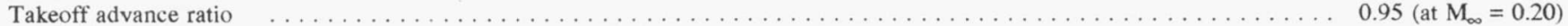

"Forward propeller/aft propeller.

Table 2.-Propeller Test Configurations

\begin{tabular}{|l|c|l|c|}
\hline Propeller & $\begin{array}{c}\text { Blade setting angle, } \\
\text { deg forward/aft }\end{array}$ & \multicolumn{1}{|c|}{ Forward rotor shape } & $\begin{array}{c}\text { Rotor-rotor spacing, } \\
\text { cm (in.) }\end{array}$ \\
\hline F31/A31 & $34.1 / 38.2$ & Reference aft swept & $18.24(7.22)$ \\
\hline F31/A31 & $38.0 / 38.2$ & Reference aft swept & $18.24(7.22)$ \\
\hline F39/A31 & $32 / 0 / 38.2$ & $\begin{array}{l}\text { Original design, L.E. clipped } \\
\text { at } 15 \text { percent of chord }\end{array}$ & $18.24(7.22)$ \\
\hline F39/A31 & $35.3 / 38.2$ & $\begin{array}{l}\text { Original design, L.E. clipped at } \\
15 \text { percent chord and L.E. rounded } \\
4.06 \text { cm }(0.60 \text { in.) diameter }\end{array}$ & $18.24(7.22)$ \\
\hline F39/A31 & $35.0 / 38.2$ & $\begin{array}{l}\text { Rotor remanufactured for } \\
\text { additional stiffness }\end{array}$ & $18.24(7.22)$ \\
\hline F39/A31 & $35.0 / 38.2$ & $\begin{array}{l}\text { Rotor remanufactured for } \\
\text { additional stiffness and L.E. } \\
\text { clipped at 15 percent chord }\end{array}$ & $14.99(5.90)$ \\
\hline
\end{tabular}


Table 3.- Selected Aerodynamic Results

Part (a)-Forward-Swept F39/A31 Propeller

\begin{tabular}{|c|c|c|c|c|c|c|c|c|c|}
\hline \multicolumn{10}{|c|}{ Original design, 15 percent clipped leading edge } \\
\hline $\begin{array}{l}\text { Speed, } \\
\text { percent }\end{array}$ & $\begin{array}{c}\text { Spacing, }^{\mathrm{a}} \\
\mathrm{cm} \text { (in.) }\end{array}$ & $\begin{array}{c}\text { Blade } \\
\text { angle, } \\
\text { deg }\end{array}$ & $\mathrm{PQAT}_{1}{ }^{\mathrm{b}}$ & $\mathrm{PQA}_{1}$ & $\mathrm{PQA}_{2}$ & $\mathrm{~J}_{1}{ }^{\mathrm{c}}$ & $\mathrm{J}_{2}$ & $\mathrm{rpm}_{1}$ & $\mathrm{rpm}_{2}$ \\
\hline 70 & $18.24(7.22)$ & $32.0 / 38.2$ & 1.353 & 0.558 & 0.976 & 1.159 & 1.205 & 5341 & 5392 \\
\hline 75 & & & 1.552 & 0.678 & 1.082 & 1.082 & 1.129 & 5717 & 5755 \\
\hline 80 & & & 1.722 & 0.779 & 1.163 & 1.014 & 1.056 & 6097 & 6145 \\
\hline 85 & & & 1.859 & 0.853 & 1.246 & 0.952 & 0.993 & 6488 & 6529 \\
\hline
\end{tabular}

Original design, rounded and 15 percent clipped leading edge

\begin{tabular}{|c|c|c|c|c|c|c|c|c|c|}
\hline 70 & $18.24(7.22)$ & $35.3 / 38.2$ & 1.744 & 0.928 & 0.996 & 1.173 & 1.218 & 5361 & 5422 \\
\hline 75 & & & 1.910 & 1.032 & 1.096 & 1.100 & 1.150 & 5716 & 5737 \\
\hline 80 & & & $\mathrm{n} / \mathrm{a}$ & $\mathrm{n} / \mathrm{a}$ & $\mathrm{n} / \mathrm{a}$ & $\mathrm{n} / \mathrm{a}$ & $\mathrm{n} / \mathrm{a}$ & $\mathrm{n} / \mathrm{a}$ & $\mathrm{n} / \mathrm{a}$ \\
\hline 85 & & & 2.257 & 1.226 & 1.270 & 0.973 & 1.013 & 6460 & 6514 \\
\hline
\end{tabular}

Remanufactured blades, design shape

\begin{tabular}{|l|l|l|l|l|l|l|l|l|l|}
\hline 70 & $18.24(7.22)$ & $35.0 / 38.2$ & 1.712 & 0.900 & 1.001 & 1.176 & 1.225 & 5352 & 5394 \\
75 & & & 1.917 & 1.012 & 1.103 & 1.103 & 1.144 & 5711 & 5780 \\
80 & & & 2.093 & 1.118 & 1.191 & 1.036 & 1.075 & 6100 & 6169 \\
83 & & & 2.210 & 1.185 & 1.265 & 0.995 & 1.036 & 6346 & 6394 \\
\hline
\end{tabular}

Remanufactured blades, 15 percent clipped leading edge

\begin{tabular}{|c|c|c|c|c|c|c|c|c|c|}
\hline 70 & $14.99(5.90)$ & $35.0 / 38.2$ & 1.692 & 0.872 & 1.006 & 1.181 & 1.228 & 5343 & 5396 \\
\hline 75 & & & 1.915 & 1.006 & 1.123 & 1.099 & 1.146 & 5725 & 5766 \\
\hline 80 & & & 2.100 & 1.104 & 1.218 & 1.030 & 1.071 & 6100 & 6165 \\
\hline 83 & & & 2.207 & 1.168 & 1.272 & 0.991 & 1.031 & 6340 & 6405 \\
\hline
\end{tabular}

Part (b), Aft-Swept F31/A31 Propeller

\begin{tabular}{|c|c|c|c|c|c|c|c|c|c|}
\hline $\begin{array}{l}70 \\
75 \\
80 \\
85 \\
90\end{array}$ & $18.24(7.22)$ & $34.1 / 38.2$ & $\begin{array}{l}1.352 \\
1.533 \\
1.702 \\
1.816 \\
1.965\end{array}$ & $\begin{array}{l}0.524 \\
0.617 \\
0.697 \\
0.759 \\
0.820\end{array}$ & $\begin{array}{l}0.961 \\
1.052 \\
1.149 \\
1.218 \\
1.295\end{array}$ & $\begin{array}{l}1.193 \\
1.111 \\
1.043 \\
0.984 \\
0.929\end{array}$ & $\begin{array}{l}1.231 \\
1.142 \\
1.070 \\
1.013 \\
0.950\end{array}$ & $\begin{array}{l}5332 \\
5712 \\
6118 \\
6463 \\
6865\end{array}$ & $\begin{array}{l}5355 \\
5756 \\
6175 \\
6508 \\
6954\end{array}$ \\
\hline $\begin{array}{l}70 \\
75 \\
80 \\
85 \\
90\end{array}$ & $18.24(7.22)$ & $38.0 / 38.2$ & $\begin{array}{l}1.711 \\
1.957 \\
2.094 \\
2.256 \\
2.400\end{array}$ & $\begin{array}{l}0.922 \\
1.016 \\
1.088 \\
1.174 \\
1.247\end{array}$ & $\begin{array}{l}0.918 \\
1.090 \\
1.159 \\
1.241 \\
1.331\end{array}$ & $\begin{array}{l}1.205 \\
1.130 \\
1.061 \\
1.001 \\
0.943\end{array}$ & $\begin{array}{l}1.244 \\
1.165 \\
1.092 \\
1.029 \\
0.971\end{array}$ & $\begin{array}{l}5356 \\
5720 \\
6099 \\
6459 \\
6871\end{array}$ & $\begin{array}{l}5376 \\
5749 \\
6140 \\
6510 \\
6913\end{array}$ \\
\hline
\end{tabular}

0-degree Angle-of-attack, $\mathrm{M}_{\infty}=0.2$.

Subscripts: 1 denotes forward rotor; 2 denotes aft rotor.

aspacing is defined as axial distance between rotor pitch changes axes.

${ }^{b} \mathrm{PQAT}$ is defined as power/ $\left[(\rho)(\mathrm{rev} / \mathrm{sec})^{3}(\mathrm{D})^{3}\right.$ (annulus area)] where $\rho$ is the freestream air density, and D is the propeller diameter.

${ }^{\mathrm{C}} \mathrm{J}$ is the propeller advance ratio, defined as $\mathrm{V}_{\infty} /(\mathrm{rpm} / \mathrm{D})$, where $\mathrm{V}_{\infty}$ is the freestream velocity, and $\mathrm{D}$ is the propeller diameter. 


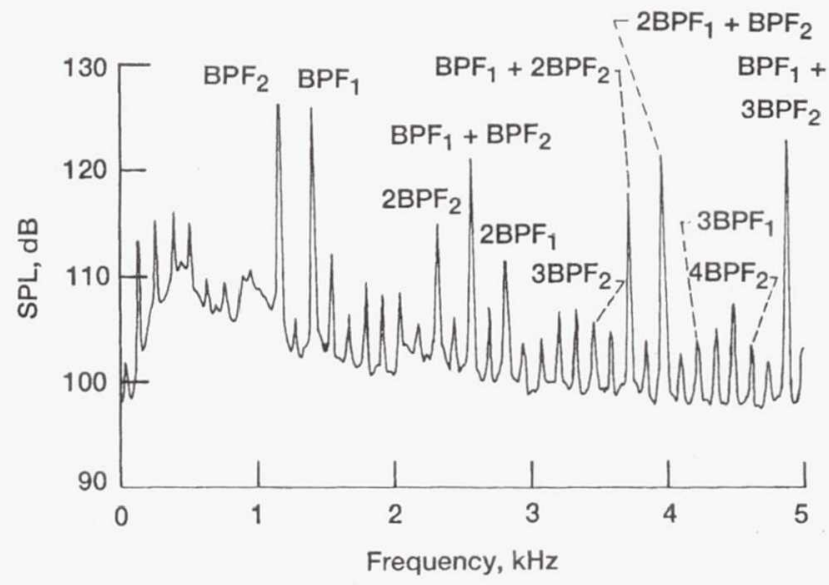

Figure 1.-Typical counterrotation turboprop sound pressure level spectrum (subscripts 1 and 2 refer, respectively, to forward and aft rotor).

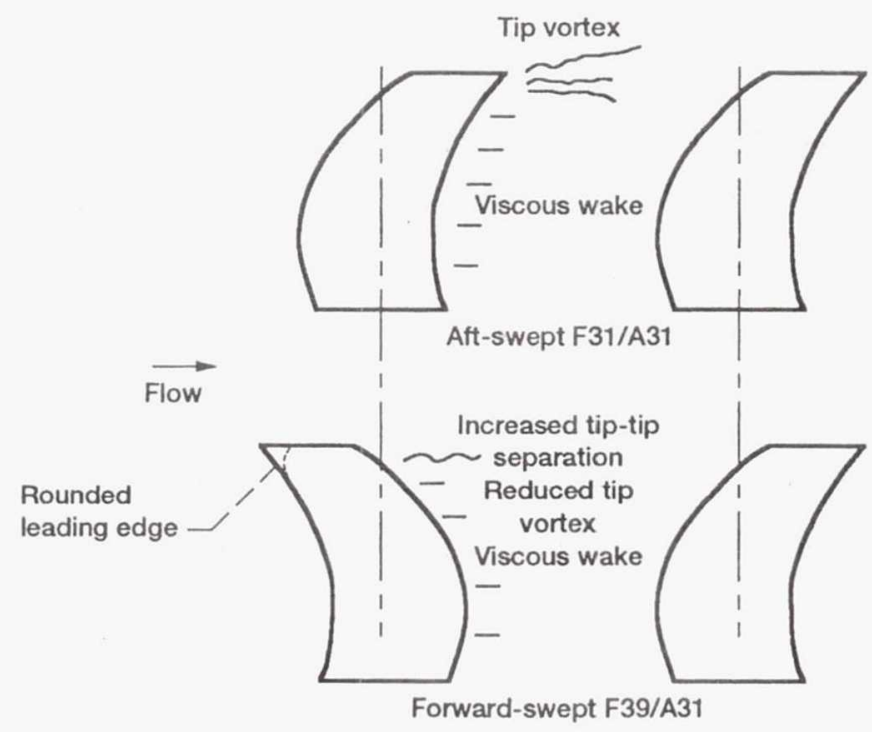

Aft-swept

- Forward rotor tip vortex is strengthened by leading edge vortex, and interacts with aft rotor.

- Forward rotor viscous wake interacts with aft rotor.

Forward-swept

- Forward rotor tip vortex has reduced intensity (little leading edge vortex contribution), and increased dissipation distance to aft rotor. Tip vortex may migrate toward hub prior to release.

- Forward rotor viscous wake interaction with aft rotor may be more significant at mid-radius due to closer rotor-rotor spacing.

Figure 2.-Aeroacoustic comparison of forward- and aft-swept counterrotation propeller concepts. 


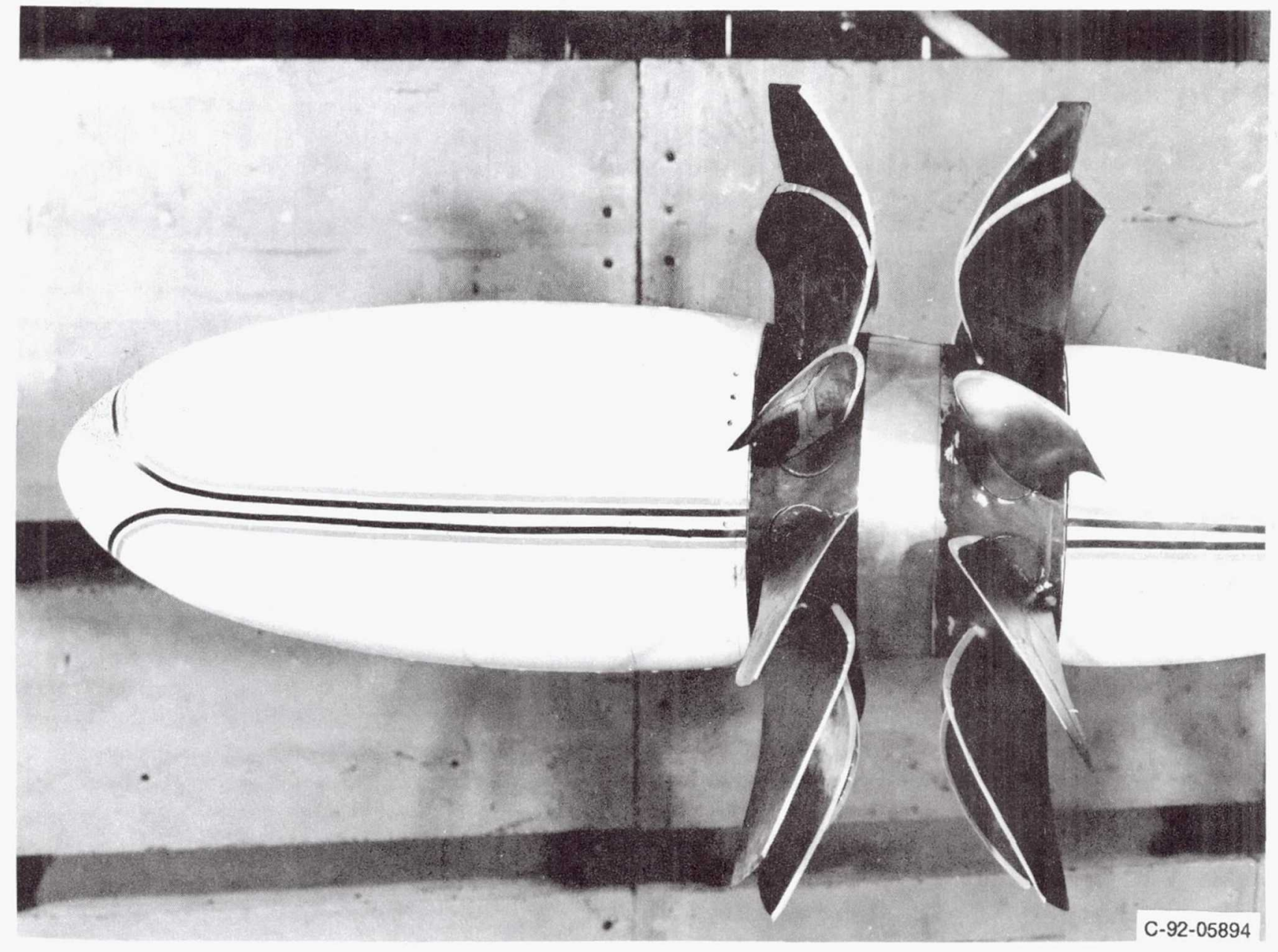

Figure 3.-F39/A31 forward-swept counterrotation turboprop. 


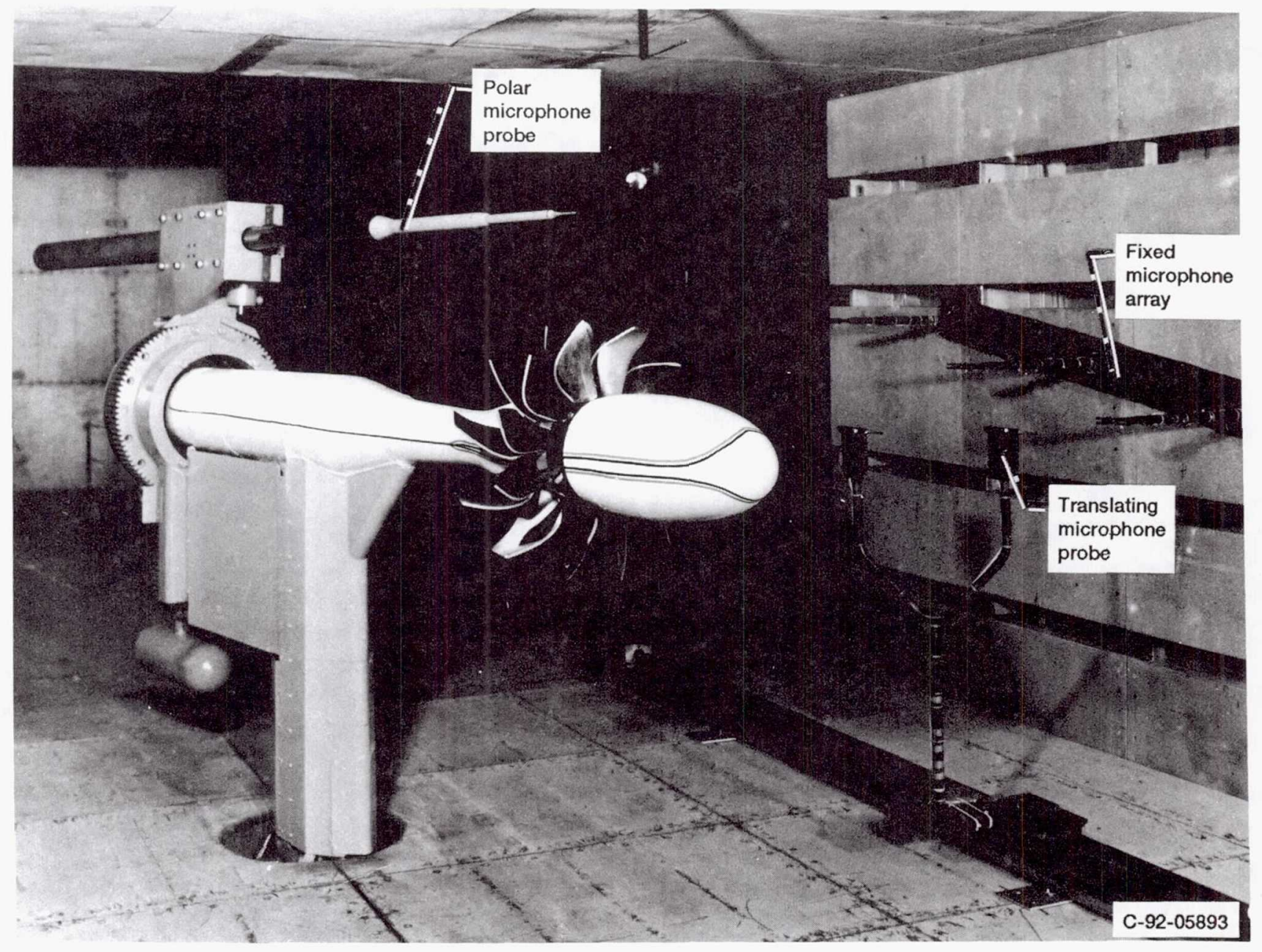

Figure 4.-Photograph of forward-swept counterrotation propeller installed in the 9x15 anechoic wind tunnel. 
Polar microphone probe

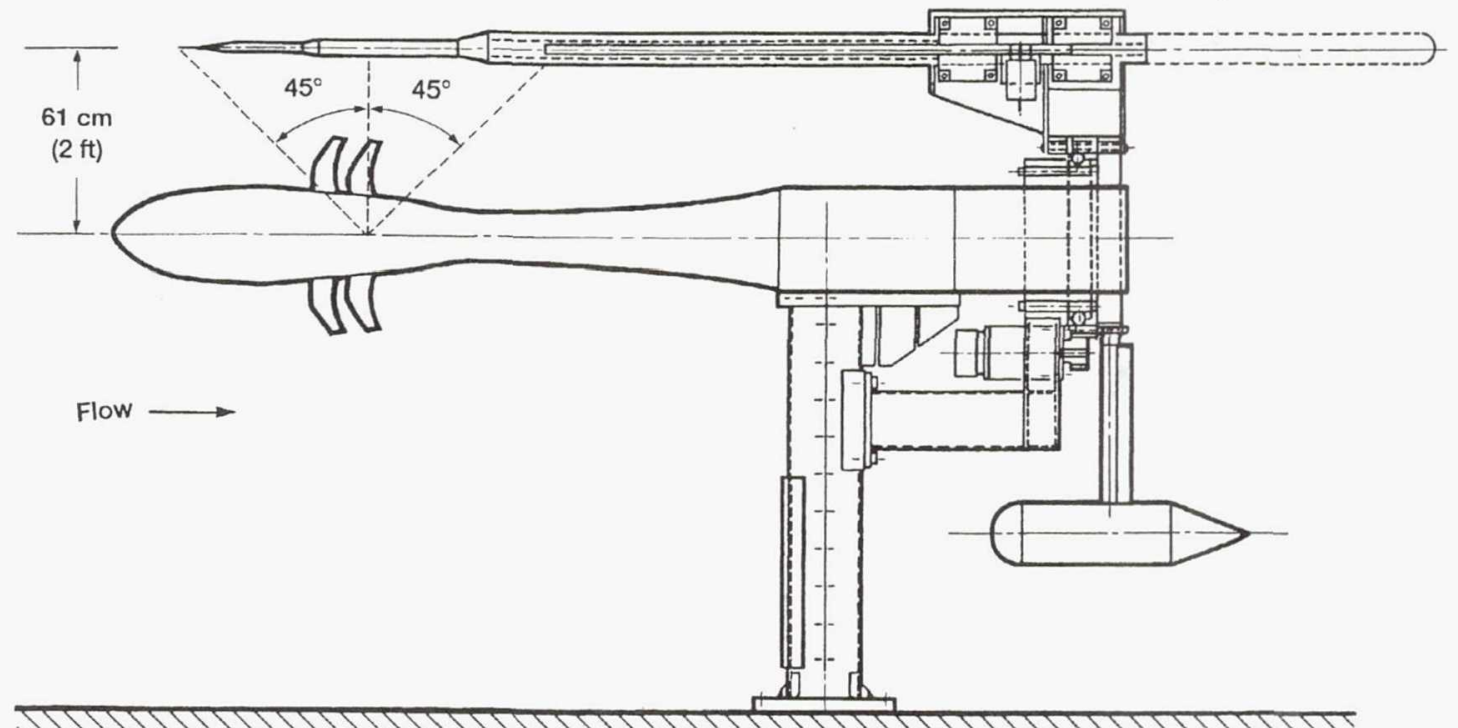

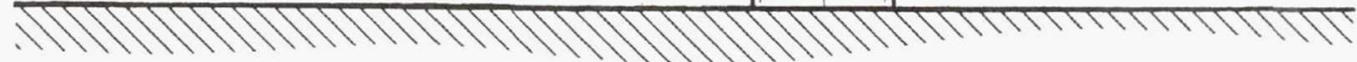

Figure 5.-Sketch of the turboprop model and polar microphone probe.

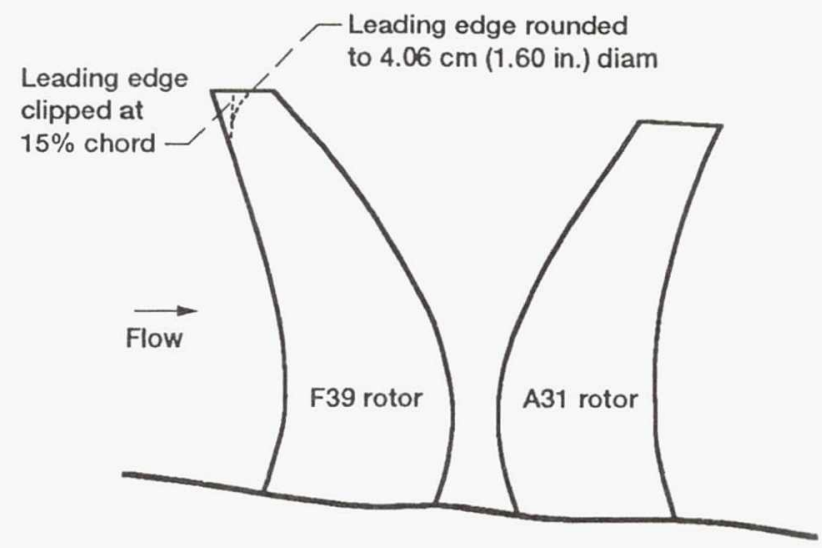

Figure 6.-Modifications to F39 rotor tip region (actual rotorrotor spacing was greater than indicated in this sketch). 


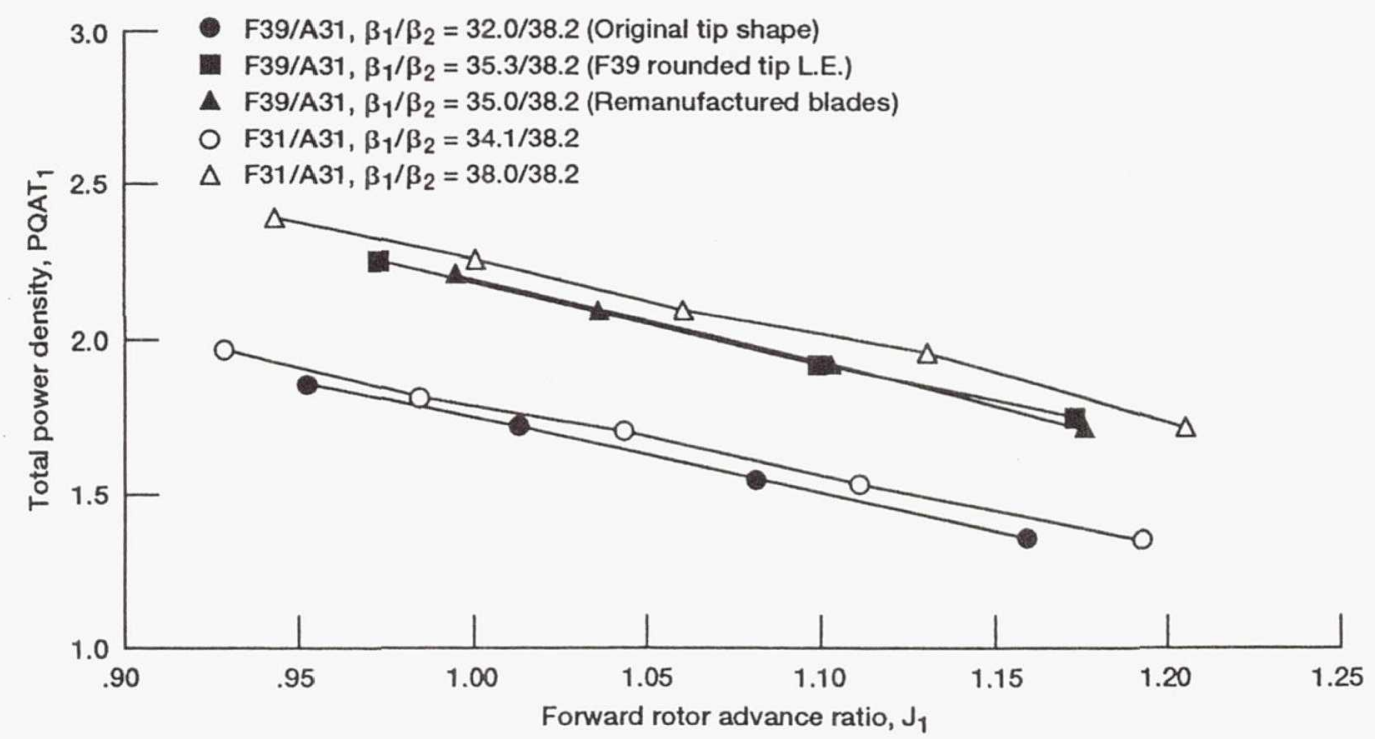

Figure 7. - Forward- and aft-swept counterrotating propeller aerodynamic performance $\left(\alpha=0^{\circ}, M_{\infty}=0.20\right)$.

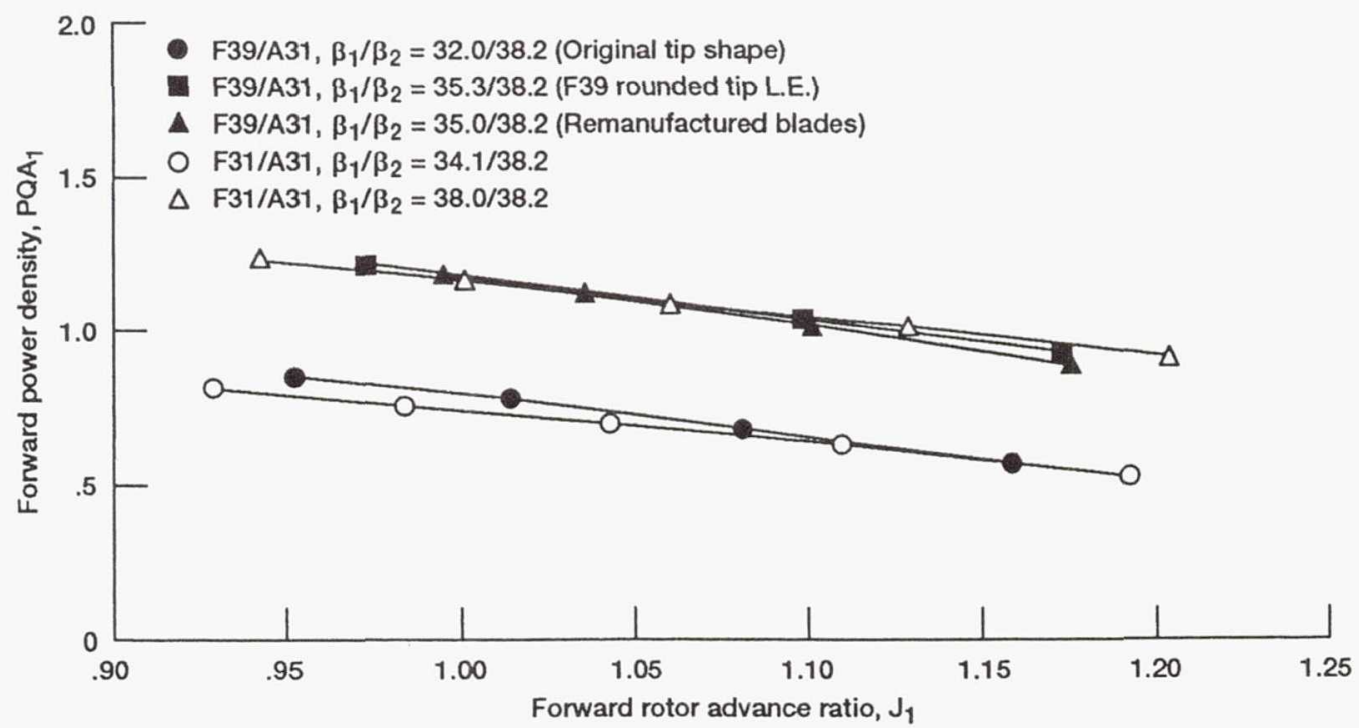

Figure 8.-Forward rotor power density as a function of advance ratio $\left(\alpha=0^{\circ}, M_{\infty}=0.20\right)$. 


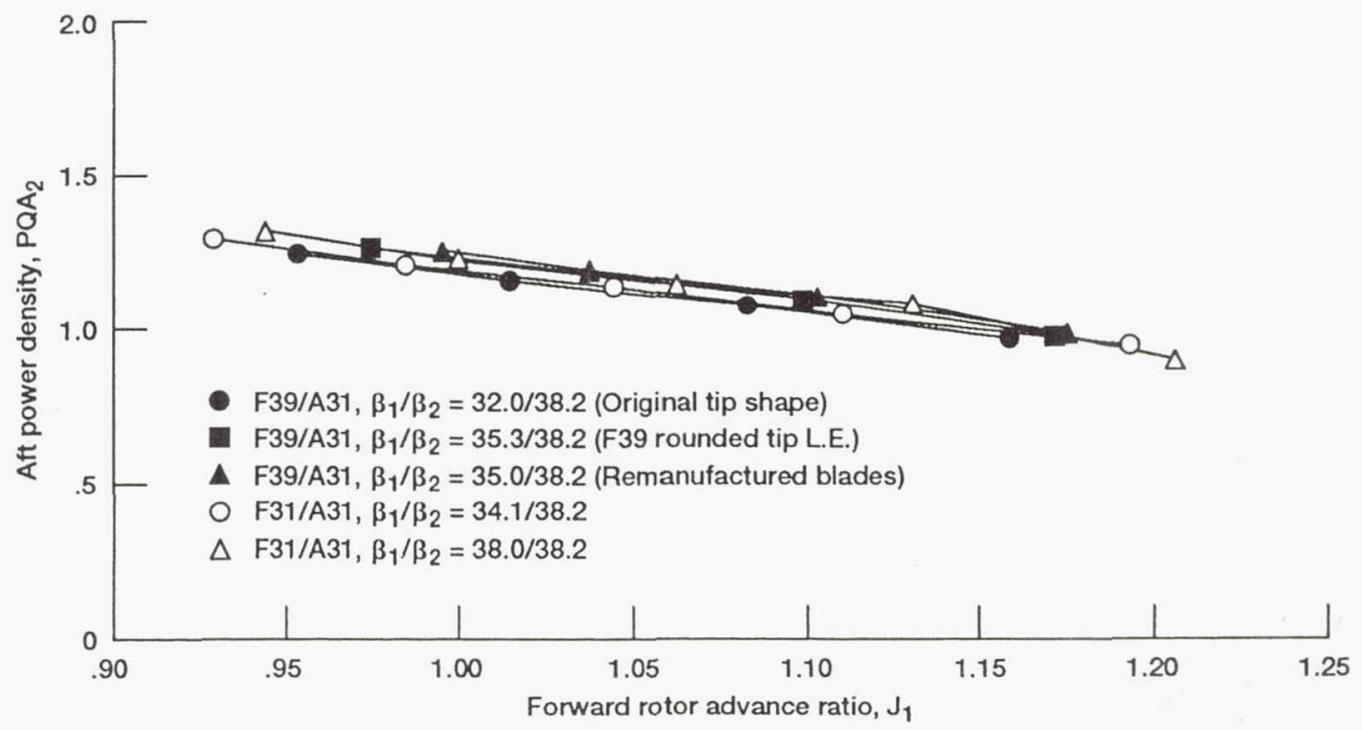

Figure 9.-Aft rotor power density as a function of advance ratio $\left(\alpha=0^{\circ}, M_{\infty}=0.20\right)$.

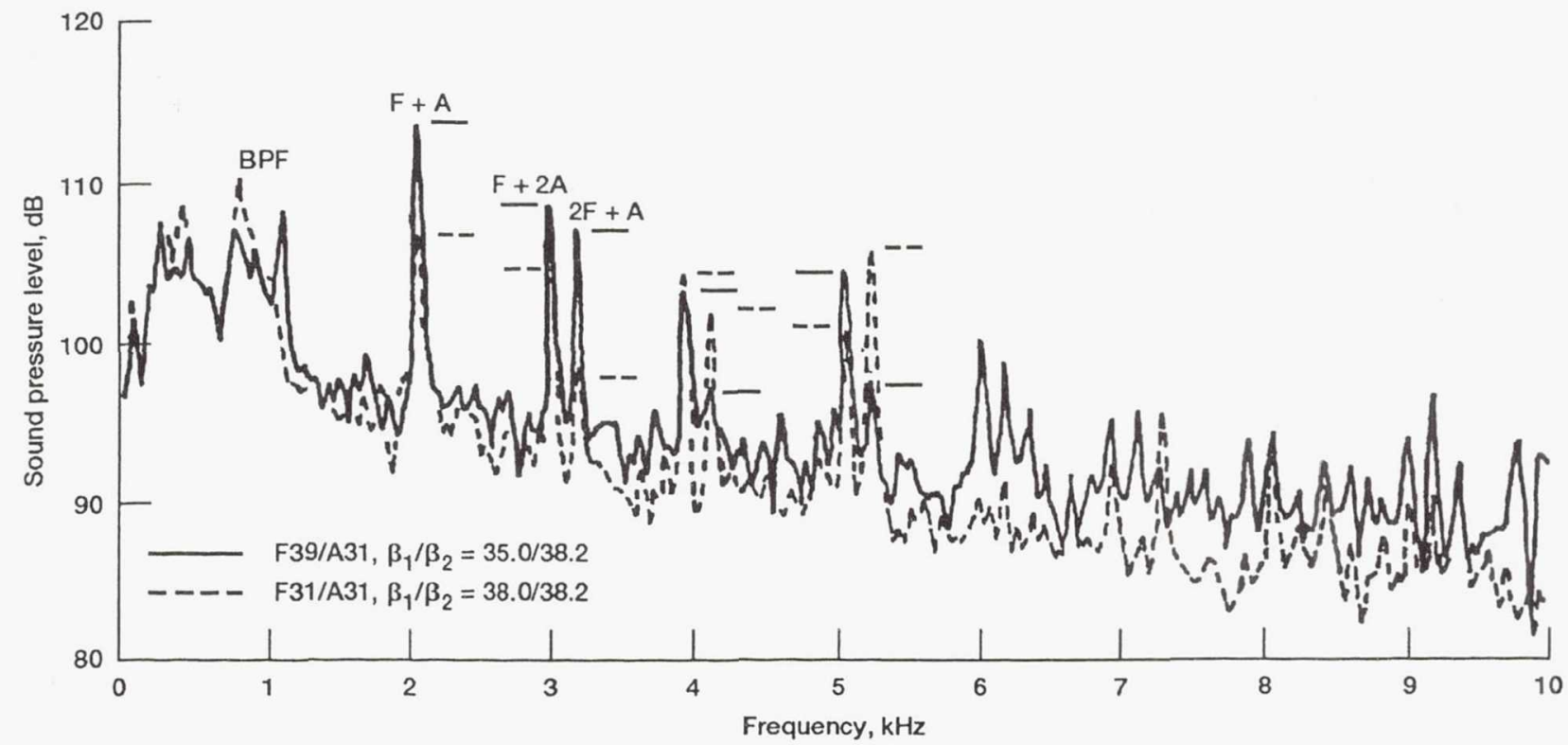

Figure 10.-Comparison of SPL spectra for forward- and aft-swept propellers ( $32 \mathrm{~Hz}$ bandwidth, $\theta=82^{\circ}, \alpha=0^{\circ}, 75 \%$ design speed, $M_{\infty}=0.20$ ). 


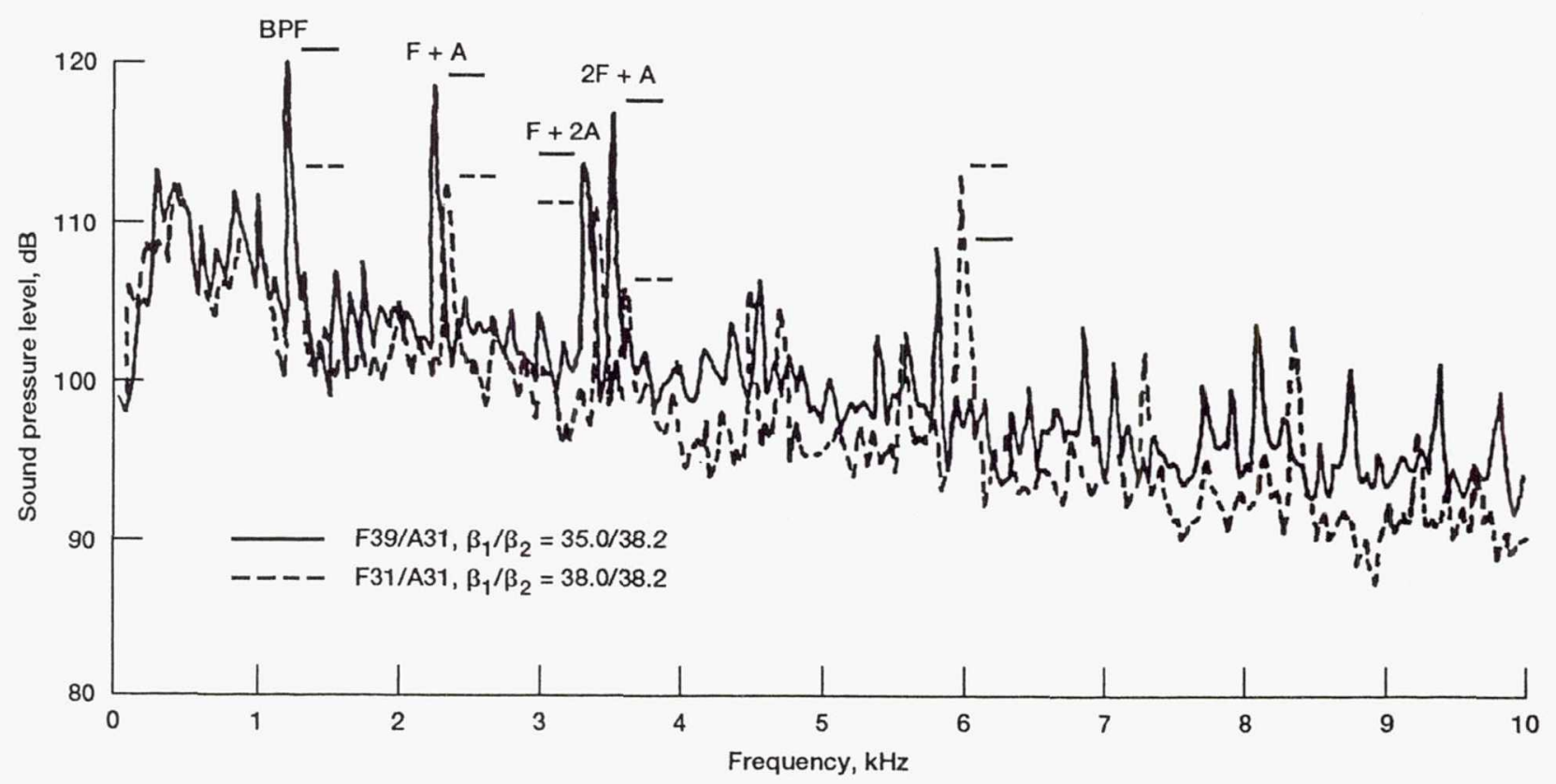

Figure 11. Comparison of SPL spectra for forward- and aft-swept propellers $\left(32 \mathrm{~Hz}\right.$ bandwidth, $\theta=82^{\circ}, \alpha=0^{\circ}, \mathrm{F} 39 / \mathrm{A} 31$ at $83 \%$ design speed, $F 31 / A 31$ at $85 \%$ design speed, $M_{\infty}=0.20$ ). 


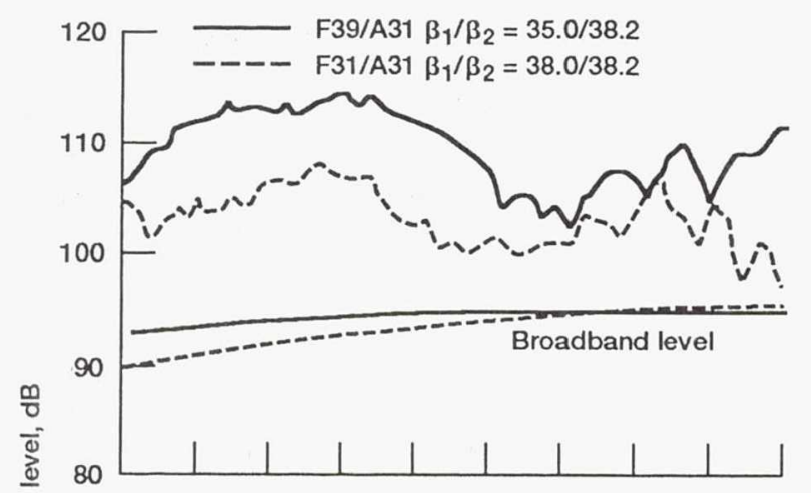

(a) $\mathrm{F}+\mathrm{A}$ interaction tone.

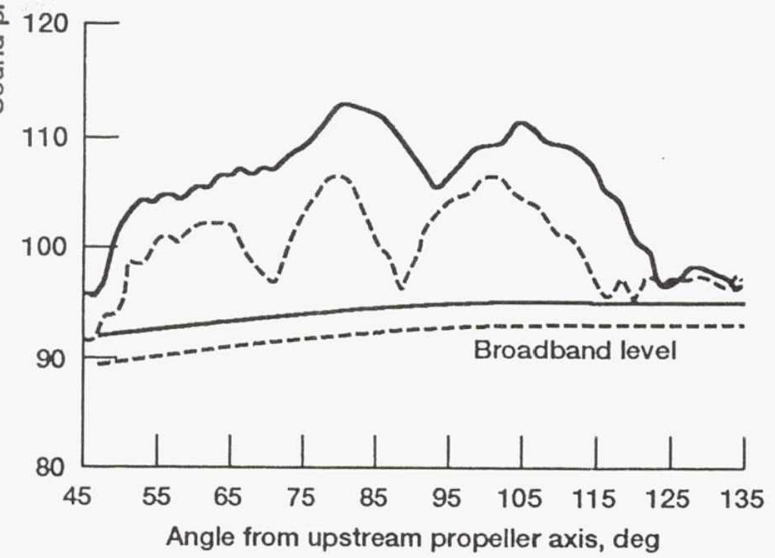

(b) $2 \mathrm{~F}+\mathrm{A}$ interaction tone.

Figure 12.-Sideline tone directivity $(61 \mathrm{~cm} \mathrm{(24} \mathrm{in.)} \mathrm{sideline,}$ $\alpha=0^{\circ}, 75 \%$ design speed, $M_{\infty}=0.20$ ).

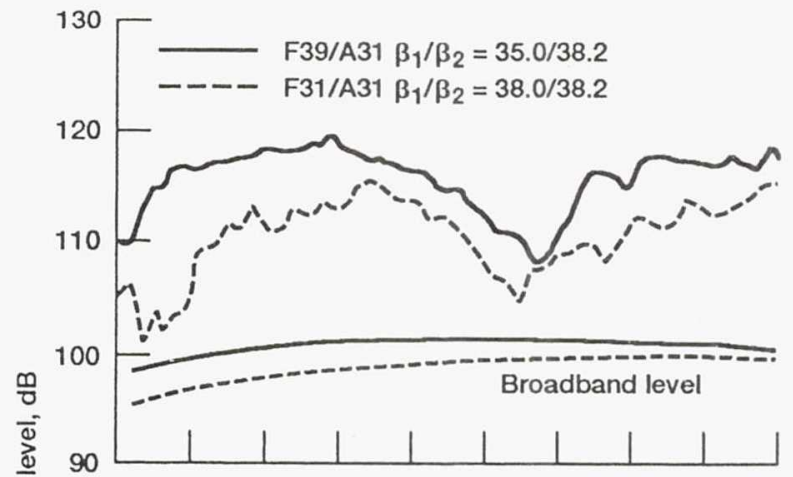

(a) $\mathrm{F}+\mathrm{A}$ interaction tone.

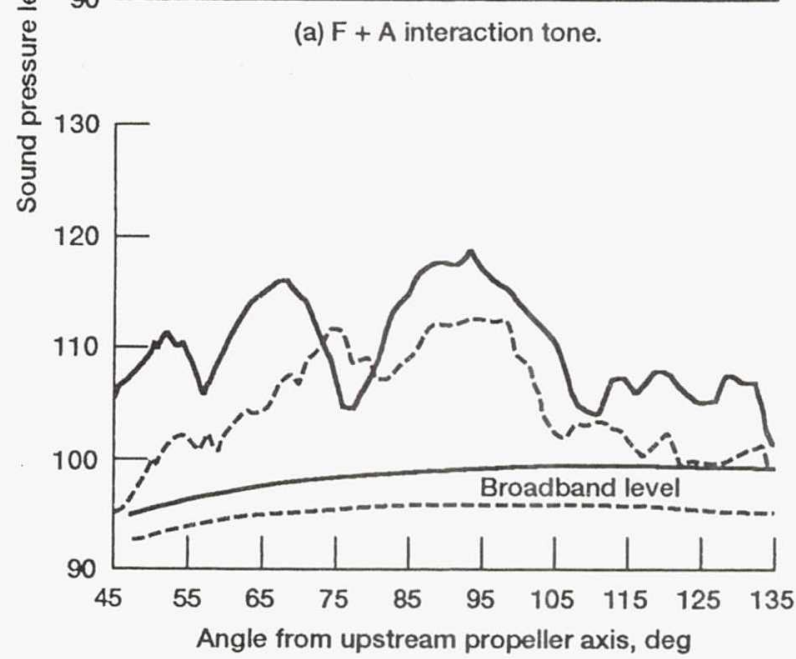

(b) $2 \mathrm{~F}+\mathrm{A}$ interaction tone.

Figure 13. - Sideline tone directivity $(61 \mathrm{~cm}(24 \mathrm{in}$.) sideline, $\alpha=0^{\circ}, \mathrm{F} 39 / \mathrm{A} 31$ at $83 \%$ design speed, F31/A31 at $85 \%$ design speed, $M_{\infty}=0.20$ ). 


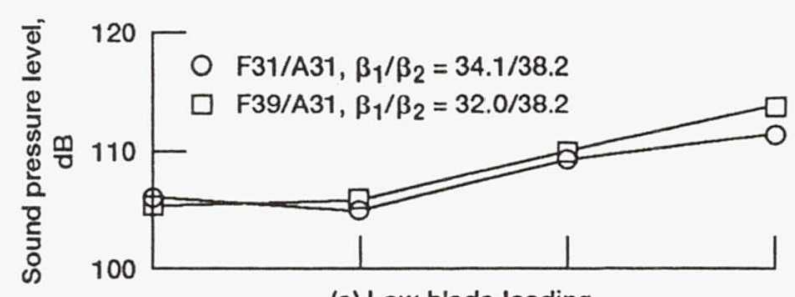

(a) Low blade loading.

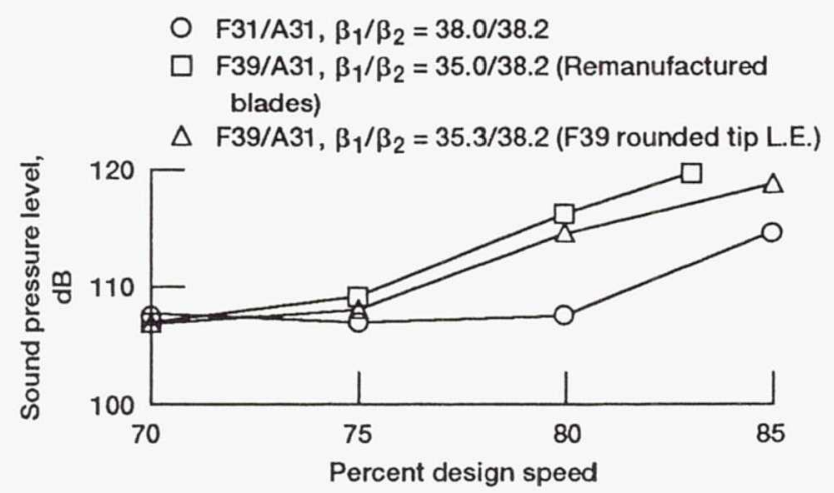

(b) Intermediate blade loading.

Figure 14.-Maximum forward rotor BPF tone level along a $61 \mathrm{~cm}$ (24 in.) sideline as a function of propeller percent design speed. $\left(\alpha=0^{\circ}, M_{\infty}=0.20\right)$.

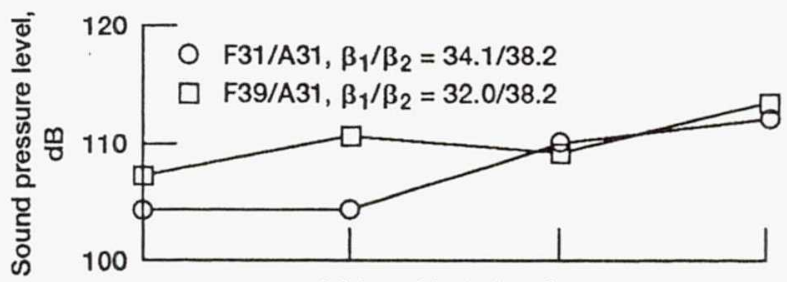

(a) Low blade loading.

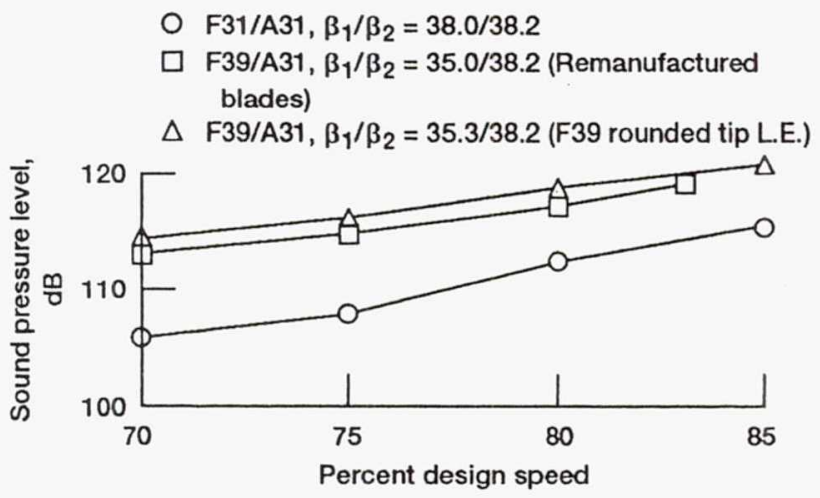

(b) Intermediate blade loading.

Figure 15.-Maximum $\mathrm{F}+\mathrm{A}$ interaction tone level along a $61 \mathrm{~cm}$ (24 in.) sideline as a function of propeller percent design speed. $\left(\alpha=0^{\circ}, M_{\infty}=0.20\right)$.

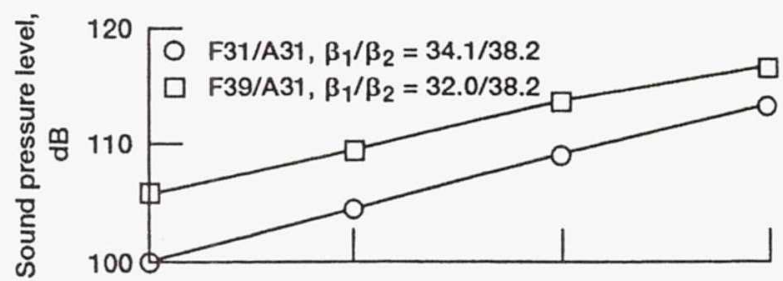

(a) Low blade loading.

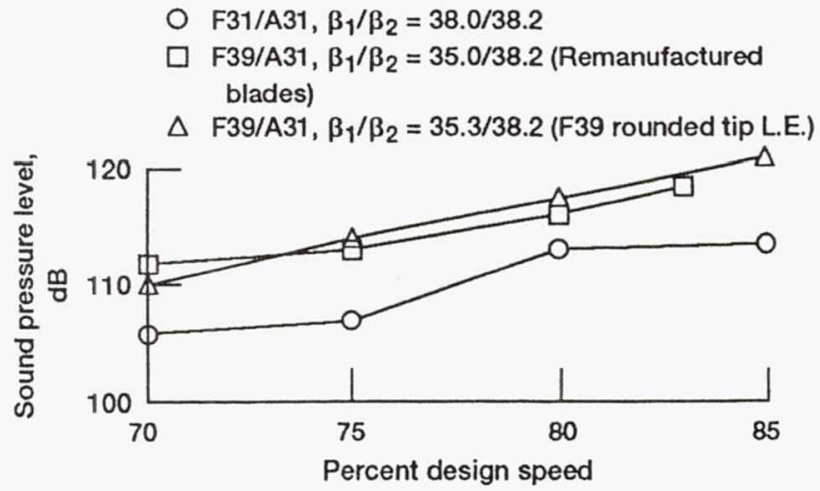

(b) Intermediate blade loading.

Figure 16.-Maximum $2 \mathrm{~F}+\mathrm{A}$ interaction tone level along a $61 \mathrm{~cm}$ (24 in.) sideline as a function of propeller percent design speed. $\left(\alpha=0^{\circ}, \mathrm{M}_{\infty}=0.20\right)$. 

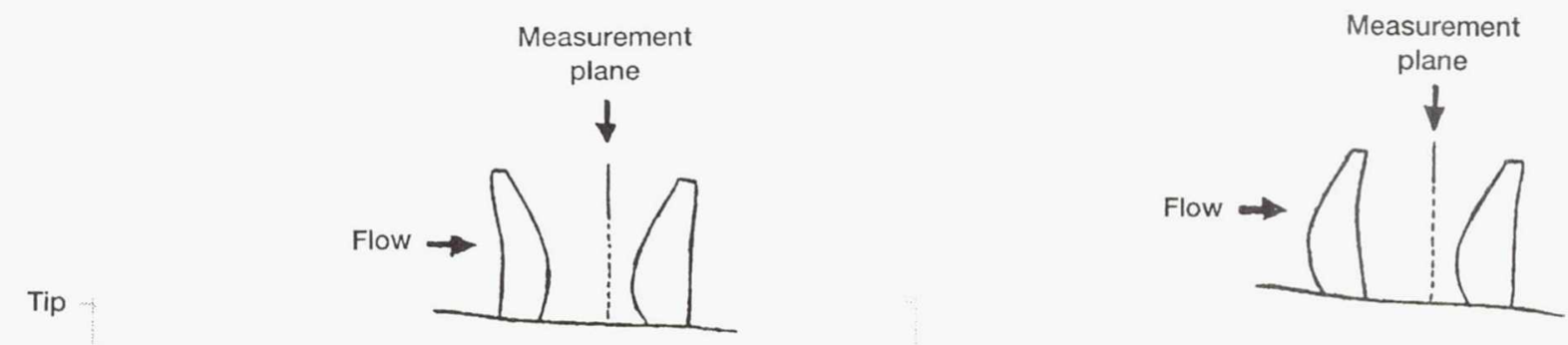

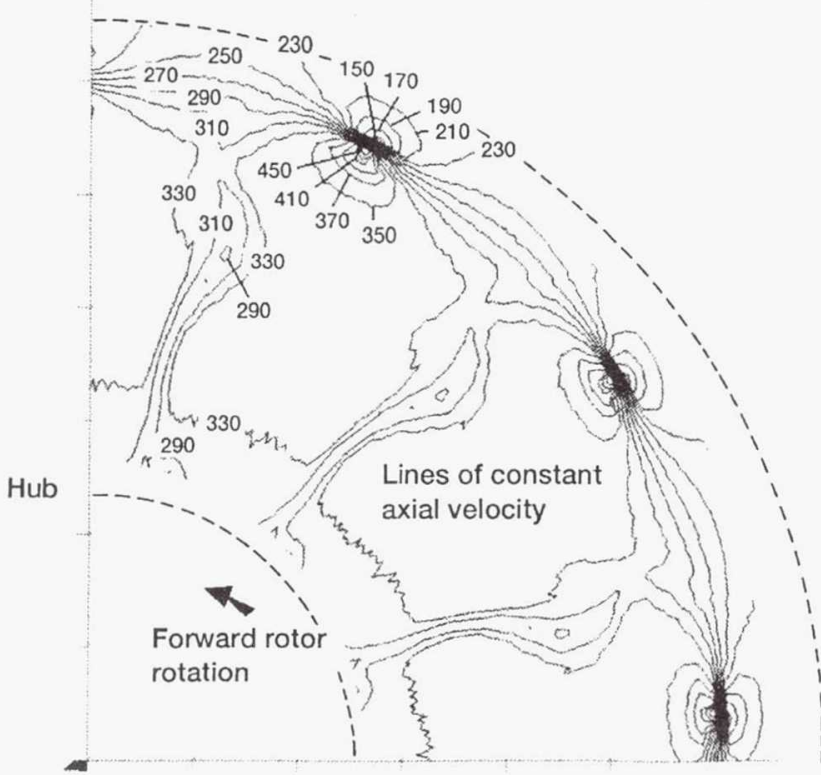

(a) Forward-swept propeller, F39/A31.

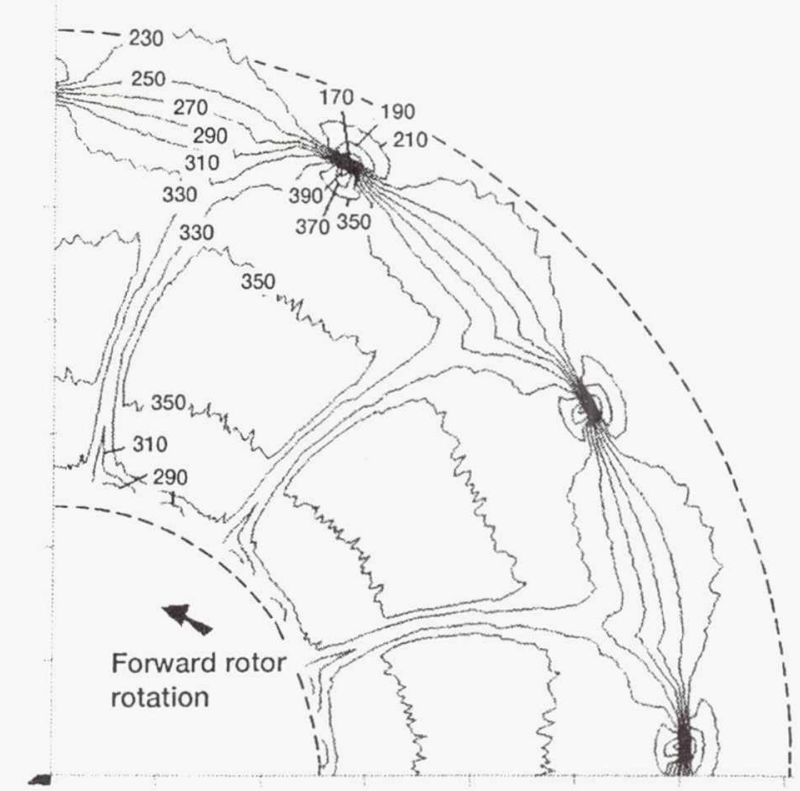

(b) Aft-swept propeller, F31/A31.

Figure 17.- Inter-blade row axial velocity profiles from laser Doppler velocimetry measurements (viewing upstream, F39/A31 $\beta_{1} / \beta_{2}=32.0^{\circ} / 38.2^{\circ}$, F31/A31 $\beta_{1} / \beta_{2}=35.0^{\circ} / 38.2^{\circ}, 85 \%$ design speed, $\alpha=0^{\circ}, M_{\infty}=0.2$. 

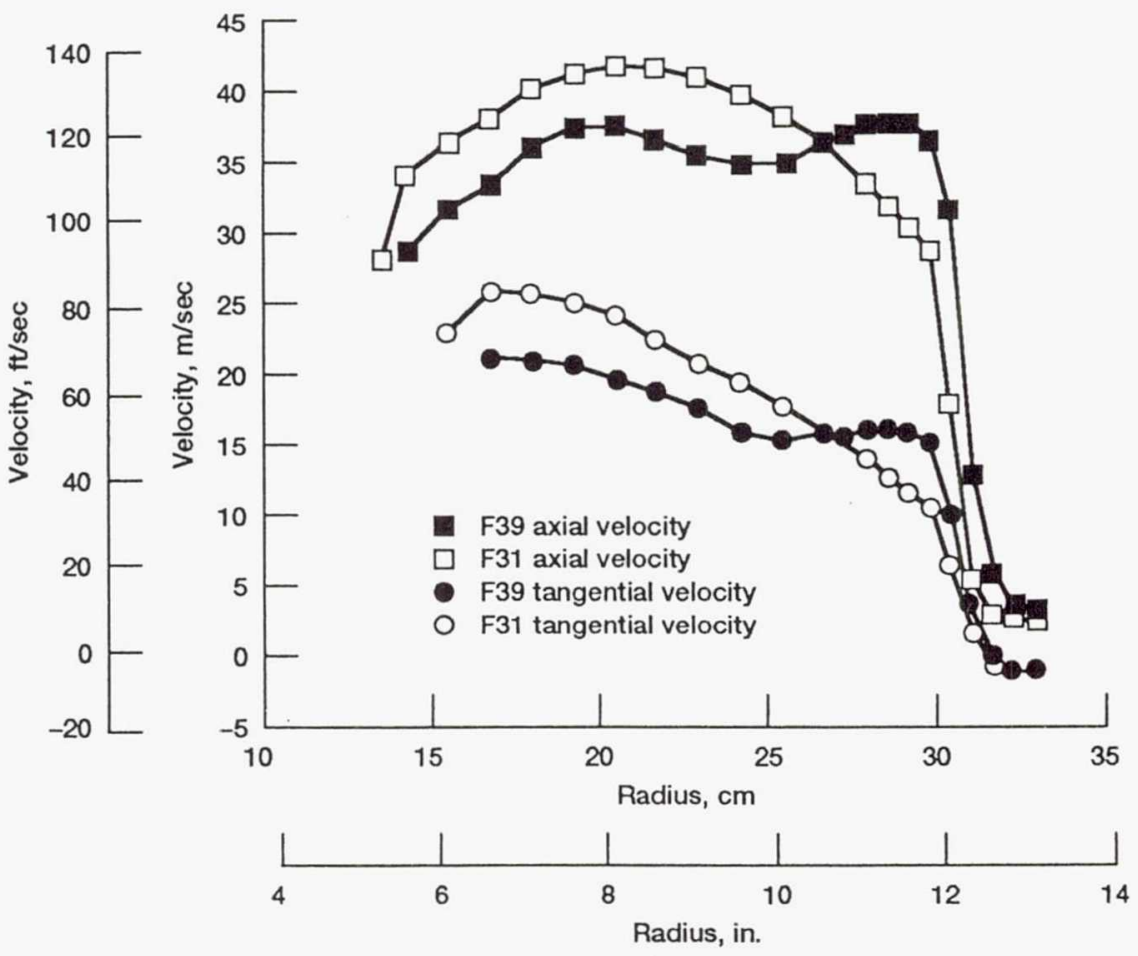

Figure 18.-Circumferentially-averaged axial and tangential velocity profiles measured downstream of forward- and aft-swept rotors ( $F 39 \beta=32.0^{\circ}, F 31 \beta=35.0^{\circ}, 85 \%$ design speed, $\alpha=0^{\circ}, M_{\infty}=0.20$ ).

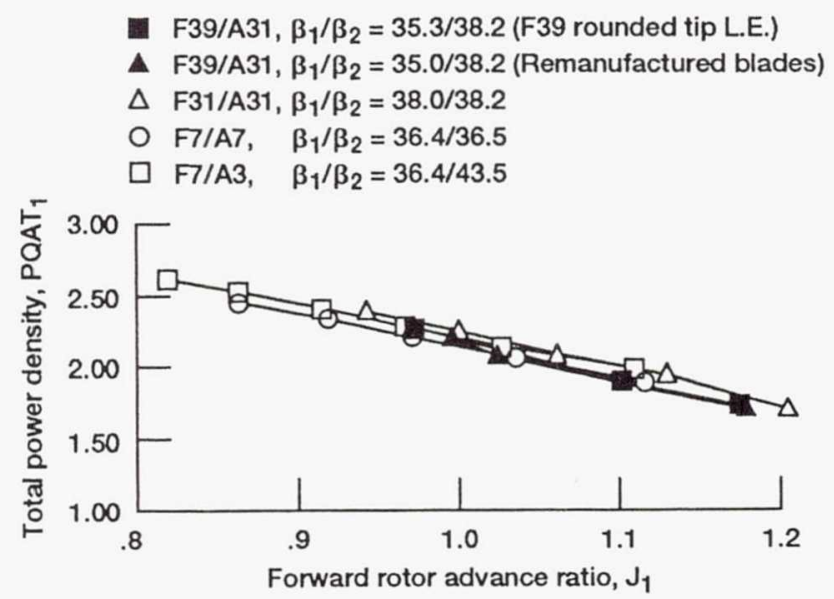

Figure 19.-Propeller operating map showing forward-swept F39/A31 propeller and reference aft-swept configurations. $\left(\alpha=0^{\circ}, M_{\infty}=0.20\right)$. 
O F 31/A31, $\beta_{1} / \beta_{2}=38.0 / 38.2,75 \%$ SPD

$\square$ F39/A31, $\beta_{1} / \beta_{2}=35.0 / 38.2,75 \%$ SPD

$\triangle$ F39/A31, $\beta_{1} / \beta_{2}=35.3 / 38.2,75 \%$ SPD F39 Rounded tip L.E.

- F7/A7, $\quad \beta_{1} / \beta_{2}=36.4 / 36.5,70 \%$ SPD

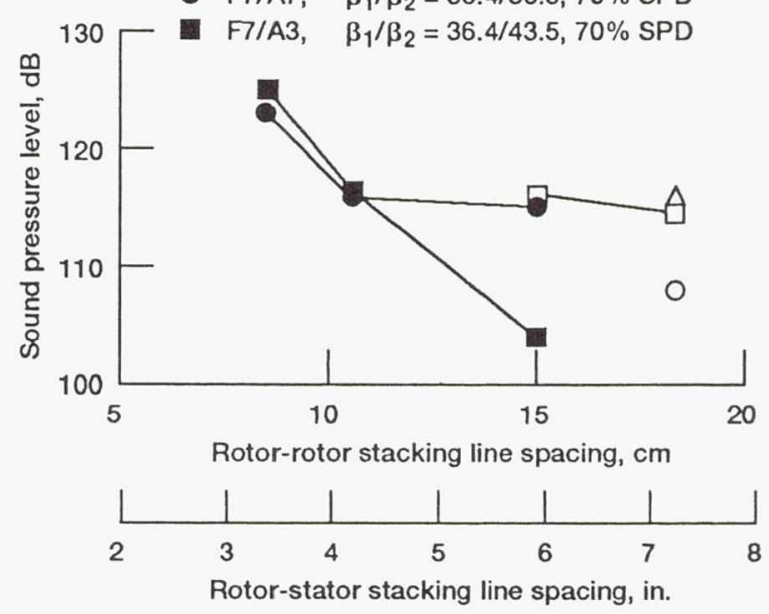

Figure 20.-Maximum F + A interaction tone level as a function of rotor-rotor axial spacing along a $61 \mathrm{~cm}(24 \mathrm{in}$.) sideline. $\left(\alpha=0^{\circ}, M_{\infty}=0.20\right)$.

O F 31/A31, $\beta_{1} / \beta_{2}=38.0 / 38.2,85 \%$ SPD

$\square$ F39/A31, $\beta_{1} / \beta_{2}=35.0 / 38.2,83 \%$ SPD

$\triangle$ F39/A31, $\beta_{1} / \beta_{2}=35.3 / 38.2,85 \%$ SPD F39 Rounded tip L.E.

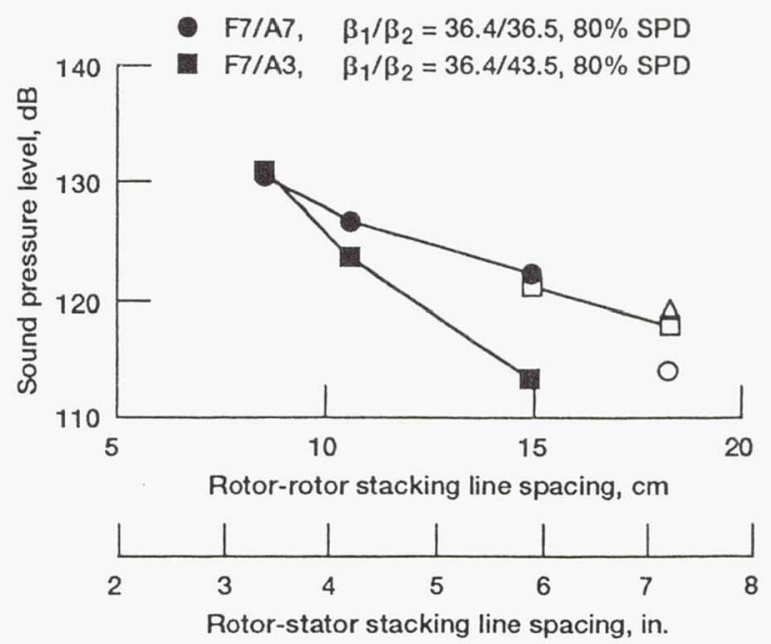

Figure 21.-Maximum $\mathrm{F}+\mathrm{A}$ interaction tone level as a function of rotor-rotor axial spacing along a $61 \mathrm{~cm}(24 \mathrm{in}$.) sideline. $\left(\alpha=0^{\circ}, M_{\infty}=0.20\right)$. 
Public reporting burden for this collection of information is estimated to average 1 hour per response, including the time for reviewing instructions, searching existing data sources, gathering and maintaining the data needed, and completing and reviewing the collection of information. Send comments regarding this burden estimate or any other aspect of this collection of information, including suggestions for reducing this burden, to Washington Headquarters Services, Directorate for information Operations and Reports, 1215 Jefferson Davis Highway, Suite 1204, Arlington, VA 22202-4302, and to the Office of Management and Budget, Paperwork Reduction Project (0704-0188), Washington, DC 20503.

\begin{tabular}{|l|l|}
\hline 1. AGENCY USE ONLY (Leave blank) & 2. REPORT DATE
\end{tabular}

January 1993

3. REPORT TYPE AND DATES COVERED

4. TITLE AND SUBTITLE

Technical Memorandum

Takeoff/Approach Noise for a Model Counterrotation Propeller with a

Forward-Swept Upstream Rotor

6. AUTHOR(S)

WU-535-03-10

Richard P. Woodward, David G. Hall, Gary G. Podboy, and Robert J. Jeracki

5. FUNDING NUMBERS

Richard P. Woodward, David G. Hall, Gary G. Podboy, and Robert J. Jeracki

7. PERFORMING ORGANIZATION NAME(S) AND ADDRESS(ES)

National Aeronautics and Space Administration

Lewis Research Center

Cleveland, Ohio 44135-3191

8. PERFORMING ORGANIZATION REPORT NUMBER

E-7479

9. SPONSORING/MONITORING AGENCY NAMES(S) AND ADDRESS(ES)

10. SPONSORING/MONITORING AGENCY REPORT NUMBER

National Aeronautics and Space Administration

Washington, D.C. 20546-0001

NASA TM-105979

\section{SUPPLEMENTARY NOTES}

Prepared for the 31st AIAA Aerospace Sciences Meeting and Exhibit sponsored by the American Institute of Aeronautics and Astronautics, Reno, Nevada, January 11-14, 1993. Richard P. Woodward, Gary G. Podboy and Robert J. Jeracki, Lewis Research Center, Cleveland, Ohio. David G. Hall, Sverdrup Technology, Inc., Lewis Research Center Group, Brook Park, Ohio 44142. Responsible person, Richard P. Woodward, (216) 433 -3923.

12a. DISTRIBUTION/AVAILABILITY STATEMENT

12b. DISTRIBUTION CODE

Unclassified - Unlimited

Subject Category 7 and 71

13. ABSTRACT (Maximum 200 words)

A scale model of a counterrotating propeller with forward-swept blades in the forward rotor and aft-swept blades in the aft rotor (designated F39/A31) has been tested in the NASA Lewis 9- by 15-Foot Anechoic Wind Tunnel. This paper presents aeroacoustic results at a takeoff/approach condition of Mach 0.20. Laser Droppler velocimeter results taken in a plane between the two rotors are also included to quantify the interaction flow field. The intention of the forward-swept design is to reduce the magnitude of the forward rotor tip vortex and/or wakes which impinge on the aft rotor, thus lowering the interaction tone levels. A reference model propeller (designated F31/A31), having aft-swept blades in both rotors, was also tested. Aero-elastic performance of the F39/A31 propeller was disappointing. The forward rotor tip region tended to untwist toward higher effective blade angles under load. The forward rotor also exhibited steady state blade flutter at speeds and loadings well below the design condition. The noise results, based on sideline acoustic data, show that the interaction tone levels were up to $8 \mathrm{~dB}$ higher with the forward-swept design compared to those for the reference propeller at similar operating conditions, with these tone level differences extending down to lower propeller speeds where flutter did not occur. These acoustic results are for a poorly-performing forward-swept propeller. It is quite possible that a properly-designed forward-swept propeller would exhibit substantial interaction tone level reductions.

\begin{tabular}{|l|l|}
\hline $\begin{array}{l}\text { 14. SUBJECT TERMS } \\
\text { Turbofan noise; Counterrotation }\end{array}$ \\
\hline $\begin{array}{c}\text { 17. SECURITY CLASSIFICATION } \\
\text { OF REPORT } \\
\text { Unclassified }\end{array}$ & $\begin{array}{c}\text { 18. SECURITY CLASSIFICATION } \\
\text { OF THIS PAGE } \\
\text { Unclassified }\end{array}$ \\
\hline
\end{tabular}

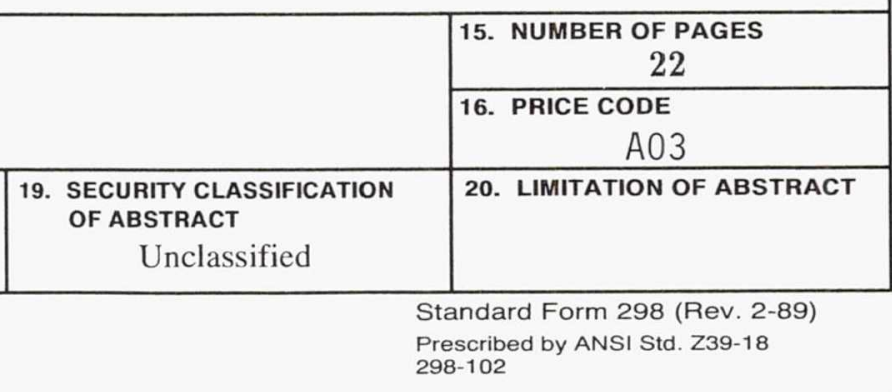


National Aeronautics and

Space Administration

Lewis Research Center

Cleveland, Ohio 44135

Official Business

Penalty for Private Use $\$ 300$

Postage and Fees Paid National Aeronautics and Space Administration NASA 451 